\title{
Improving Management Strategies of Plant Diseases Using Sequential Sensitivity Analyses
}

\author{
Loup Rimbaud, ${ }^{1}$ Sylvie Dallot, ${ }^{1}$ Claude Bruchou, ${ }^{2}$ Sophie Thoyer, ${ }^{3}$ Emmanuel Jacquot, ${ }^{1}$ \\ Samuel Soubeyrand, ${ }^{2}$ and Gaël Thébaud ${ }^{1, \dagger}$ \\ ${ }^{1}$ BGPI, INRA, Montpellier SupAgro, University of Montpellier, CIRAD, TA A-54/K, 34398 Montpellier Cedex 5, France \\ ${ }^{2}$ BioSP, INRA, Avignon, France \\ ${ }^{3}$ CEE-M, Montpellier SupAgro, INRA, CNRS, University of Montpellier, Montpellier, France \\ Accepted for publication 1 March 2019.
}

ABSTRACT

\begin{abstract}
Improvement of management strategies of epidemics is often hampered by constraints on experiments at large spatiotemporal scales. A promising approach consists of modeling the biological epidemic process and human interventions, which both impact disease spread. However, few methods enable the simultaneous optimization of the numerous parameters of sophisticated control strategies. To do so, we propose a heuristic approach (i.e., a practical improvement method approximating an optimal solution) based on sequential sensitivity analyses. In addition, we use an economic improvement criterion based on the net present value, accounting for both the cost of the different control measures and the benefit generated by disease suppression. This work is motivated by sharka (caused by Plum pox virus), a vector-borne disease of prunus
\end{abstract}

trees (especially apricot, peach, and plum), the management of which in orchards is mainly based on surveillance and tree removal. We identified the key parameters of a spatiotemporal model simulating sharka spread and control and approximated optimal values for these parameters. The results indicate that the current French management of sharka efficiently controls the disease, but it can be economically improved using alternative strategies that are identified and discussed. The general approach should help policy makers to design sustainable and costeffective strategies for disease management.

Keywords: cost-effectiveness, culling, ecology and epidemiology, PPV, roguing, SEIR, Sobol.
Improving large-scale disease management constitutes a major challenge. Faced with the urgent need to deal with emerging epidemics, one often relies on expert opinions to design management strategies, but opinions are not necessarily based on quantitative data. Some specific control methods can be tested through field trials, but they constitute only part of a global wider management strategy, which must be assessed at large spatiotemporal scales. However, at such scales, field trials are considerably limited by tractability issues, resulting in poorly generalizable results from the very few trials that might be carried out. Epidemiological models have been very helpful to overcome these obstacles and account for the interactions between biological processes and human interventions that jointly impact disease spread (Jeger et al. 2018; Parnell et al. 2017). The key epidemiological parameters of these models are prime targets for control measures. These parameters can be identified using global sensitivity analysis, as shown for invasive plants (Coutts et al. 2011), and plant pathogens, such as viruses (Chan and Jeger 1994; Holt et al. 1999; Jeger and Chan 1995; Rimbaud et al. 2018a), fungi (Papaï et al. 2014; Xu and Ridout 1998), and bacteria (Breukers et al. 2007). By varying input parameters of a simulation model within their respective variation ranges (corresponding to their

${ }^{\dagger}$ Corresponding author: G. Thébaud; gael.thebaud@inra.fr

Current address of L. Rimbaud: Pathologie Végétale, INRA, Montfavet, France.

Funding: This work was supported by a DGA-MRIS Scholarship (to L. Rimbaud), and this work was partly funded by the European Union SharCo Project, FP7 Programme and the France AgriMer Sharka project.

*The $\boldsymbol{e}$-Xtra logo stands for "electronic extra" and indicates that eleven supplementary figures and one supplementary table are published online.

The author(s) declare no conflict of interest.

(c) 2019 The American Phytopathological Society natural variation or the uncertainty on their estimates), global sensitivity analysis allows the computation of "sensitivity indices" quantifying the influence of the variability of each input parameter on a given output variable (Saltelli et al. 2008). The definition of parameter variation ranges depends on the objectives of the modeler (e.g., identifying key drivers of a biological process or identifying parameters that deserve to be better estimated) and is informed by quantitative data or expert opinions.

Some epidemiological models are used to assess the potential of different control actions in various epidemic scenarios. In this context, studies dealing with the management of perennial plant diseases have addressed management strategies based on roguing and possibly replanting (Cunniffe et al. 2014, 2015, 2016; Filipe et al. 2012; Hyatt-Twynam et al. 2017; Ndeffo Mbah and Gilligan 2010; Parnell et al. 2009, 2010; Sisterson and Stenger 2013), planting with different densities (Chan and Jeger 1994; Cunniffe et al. 2014, 2015; Jeger and Chan 1995), planting outside of contaminated areas (Chan and Jeger 1994; Filipe et al. 2012; Jeger and Chan 1995), or spraying with insecticides (Filipe et al. 2012). These studies optimized one or two control parameters under various epidemiological scenarios, but the other control parameters remained fixed at their reference value. Because control parameters generally interact each other, it is crucial to develop an alternative approach that jointly explores numerous combinations of control parameters to identify promising combinations of parameter values.

Our work is motivated by the management of sharka, the most damaging disease of prunus trees (Cambra et al. 2006). Its causal agent, Plum pox virus (PPV; genus Potyvirus), is naturally transmitted by $>20$ aphid species in a nonpersistent manner (Labonne et al. 1995) and has spread worldwide because of human shipping and planting of infected material (Cambra et al. 2006). Faced with the threat posed by sharka, various management strategies have been adopted in different countries (Rimbaud et al. 2015). In countries targeting disease limitation (e.g., France) or eradication (e.g., United States), a key element of the management 
strategy is the appropriate surveillance of nurseries and orchards followed by tree removals. Surveillance methods rely on leaf sampling followed by serological or molecular diagnostic tests or alternatively, visual inspection of prunus trees to detect sharka symptoms (mostly on leaves and fruits). When infected trees are detected, they are culled to remove sources of inoculum. Because of its long incubation period, PPV infection may remain undetected for several months or years after inoculation, regardless of the surveillance method (Quiot et al. 1995; Sutic 1971). Combined with evidence of short-distance transmission of PPV (Dallot et al. 2003; Gottwald et al. 2013; Pleydell et al. 2018), this delay explains why nonsymptomatic trees surrounding detected trees may need to be removed as well. In France, sharka management is compulsory, and a national decree specifies the control actions mentioned above (JORF 2011). In particular, this decree describes a procedure defining the frequency of visual surveillance of orchards depending on their distance to the nearest detected infection, the removal of whole orchards if their annual contamination rate exceeds a given threshold, and the conditions for replanting. This strategy is based on expert opinions and not based on quantitative data or a formal demonstration of its efficiency. In addition, it is expensive (and complex) to implement. It is thus crucial to conduct a formal costbenefit analysis and identify improved management rules.

The three objectives of this work are (i) the development of a heuristic approach (i.e., a practical method, not guaranteed to be optimal, but instead, sufficient for reaching a goal) to improve management strategies of epidemics using sequential sensitivity analyses, (ii) the design of an economic criterion that accounts for the balance between the costs induced by control actions and the benefits of reducing epidemic damage, and (iii) the identification of economically improved alternatives to the current French strategy to manage sharka. To do so, we use a spatiotemporal model initially developed in previous studies (Pleydell et al. 2018; Rimbaud et al. 2018a). This model simulates the turnover of peach orchards in a real landscape, recurrent PPV introductions at planting, and PPV spread by aphid vectors; a previous article presented an in-depth analysis of the model sensitivity to the included epidemiological parameters (Rimbaud et al. 2018a). In this work, we implemented in this model an explicit management strategy, which is flexible enough to encompass sharka management in several countries, including France. Consequently, the identified strategies should be of interest to the countries targeting area-wide management of sharka and more generally, perennial plant diseases.

\section{MATERIALS AND METHODS}

Model description. Model overview. We use a stochastic, spatially explicit, susceptible-exposed-infectious-removed (SEIR) model developed to simulate sharka epidemics in a real cultivated landscape (Pleydell et al. 2018; Rimbaud et al. 2018a). This landscape, typical of a peach-growing area in southeastern France, comprises 553 patches (i.e., land parcels, which are not necessarily contiguous), representing a total area of 524 ha (average patch area: 0.95 ha) (S1 map in Rimbaud et al. 2018a). Each patch is cultivated with a succession of peach orchards (i.e., a peach crop planted at a given date, with an average density of $\sim 720$ trees $^{\prime} \cdot \mathrm{ha}^{-1}$ ). The model is patch based, with a discrete time step of 1 week. Each host is in one of five health states (Fig. 1A). The epidemic process and the transitions between states were described previously (Pleydell et al. 2018; Rimbaud et al. 2018a). Briefly, at the beginning of the simulation, PPV is introduced for the first time (via orchard planting) in a single patch identified using its connectivity with other patches, $q_{\kappa}$. We define the connectivity of a patch as the mean number of infectious aphids that would leave this patch if all trees in this patch were infectious, and land in the other patches of the landscape. Thus, $q_{\kappa}$ depends on the patch area and proximity to other patches, and it relates to its potential to initiate an epidemic. Additional introductions can occur at every orchard planting with probability $\Phi$. At each introduction, the prevalence (i.e., the proportion of infected trees in the orchard at the time of planting) $\tau$ is drawn from a mixture distribution favoring high or low prevalence depending on the relative probability of massive introduction, $p_{M I}$. After introduction in orchards, the pathogen is spread by aphid vectors at a distance that depends on their dispersal kernel parameterized by the mean $\left(W_{\text {exp }}\right)$ and the variance $\left(W_{\text {var }}\right)$ of a dispersal variable (Rimbaud et al. 2018a has details). Healthy trees (susceptible state S) (Fig. 1A) become infected (exposed state E) when successfully inoculated by infectious aphid vectors (the probability of infection depends on the aphid transmission coefficient $\beta$ ). After a latent period (drawn from a Gamma distribution with mean duration $\theta_{\text {exp }}$ and variance $\theta_{\text {var }}$ and truncated in such way that the latent period cannot end within the growing season in which the host is infected), infected trees become infectious and symptomatic (hidden state $\mathrm{H}$; i.e., these trees are not yet detected), from where they may be detected (state D; with probability $\rho$ ). After detection, hosts are culled (removed state R) after a mean delay $\delta$ and at the latest, by the end of the year (using a truncated Geometric distribution). It is assumed that infectious (i.e., symptomatic) trees are no longer productive because of disease-induced fruit loss or ban on fruit sales. However, the disease is not supposed to affect host lifespan (no available data report any increase in prunus mortality owing to PPV); thus, hosts can reach state $\mathrm{R}$ only if removed. Because of orchard turnover (independent of the disease; simulated by drawing orchard duration from a Poisson distribution with mean $\psi=15$ years), whole orchards can be replaced by trees in state $\mathrm{S}$ (or possibly, $\mathrm{H}$ ). Table 1 summarizes all of the model parameters.

In this work, we complemented the existing model with an explicit disease management strategy. After an initial epidemic period (arbitrarily fixed at 5 years to enable pathogen establishment), a strategy based on orchard surveillance, tree removals, and replanting restrictions is applied during 30 years (which is twice the mean lifespan of the hosts and consequently, a reasonable duration in which to assess the efficiency of a management strategy). The reference management strategy is based on the French management of sharka in prunus orchards (JORF 2011). Nevertheless, our model allows a multitude of variations on each control measure, which make it possible to include some aspects of sharka management in other countries (e.g., removal radius around detected trees as in the United States) (Gottwald et al. 2013). The simulated management strategy is defined by 24 parameters (14 for surveillance, 6 for removals, and 4 for replanting restrictions) (Fig. 1 and Table 1).

Each year, orchard surveillance, removals, and planting bans depend on the location of the corresponding patch relative to previously infected trees and the local contamination rate in the preceding year. Let $\Omega$ denote the set of orchards composing the area where the contamination rate is measured (i.e., all orchards cultivated in patches in which the border is within a given radius of the centroid of the focal patch), let $D_{i, a}^{+}$denote the number of trees detected in orchard $i(i=1, \ldots, I)$ during year $a\left(a=1, \ldots, a_{f}\right)$, and let $N_{i}$ denote the initial number of trees planted in this orchard. Then, the contamination rate in this area for year $a$ is

$$
q_{a}=\frac{\sum_{i \in \Omega} D_{i, a}^{+}}{\sum_{i \in \Omega} N_{i}}
$$

Note that this measure is neither an annual incidence (i.e., the number of detected trees divided by the number of trees at the beginning of the year) nor a prevalence, but the number of detected trees divided by the number of trees at orchard planting, which is easier to calculate directly by plant health services in the field.

Orchard surveillance. All orchards are surveyed visually for disease at least once every $1 / \eta_{O}$ years (hence, $\eta_{O}$ is the basic surveillance frequency), and at each survey, symptomatic hosts (in state $\mathrm{H})$ are independently detected with probability $\rho$. Detection of a symptomatic tree triggers the definition (for the $\gamma_{o}$ following years) of nested concentric zones around the corresponding orchard (Fig. 1B). 
Within the focal zone, with a radius $\zeta_{f}$, orchards are surveyed $\eta_{f}$ times per year. Furthermore, an "observation epicenter," which is nested within the focal zone and has a radius of $\zeta_{e O}\left(\zeta_{e O}<\zeta_{f}\right)$, is defined to calculate the contamination rate (noted $q_{e O}$ ). If the contamination rate of the observation epicenter exceeds a threshold $\chi_{o}$, the surveillance frequency in the focal zone is changed to $\eta_{f^{*}}$. Within the security zone, which extends from the outer boundary of the focal zone to a radius $\zeta_{s}$ $\left(\zeta_{s}>\zeta_{f}\right)$, orchards are surveyed $\eta_{s}$ times per year.

\section{A Model architecture}

\section{B Surveillance}
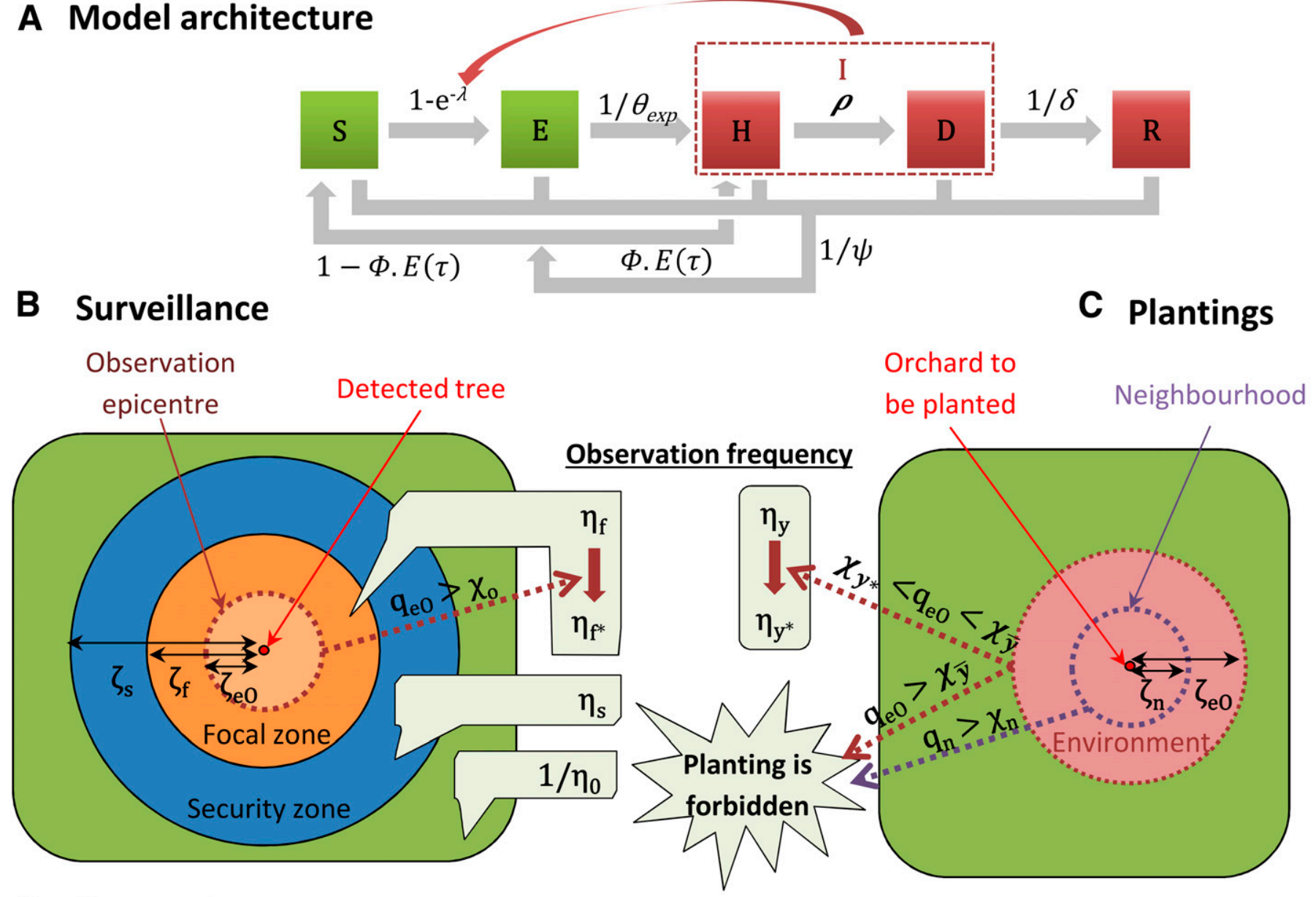

\section{Removals}

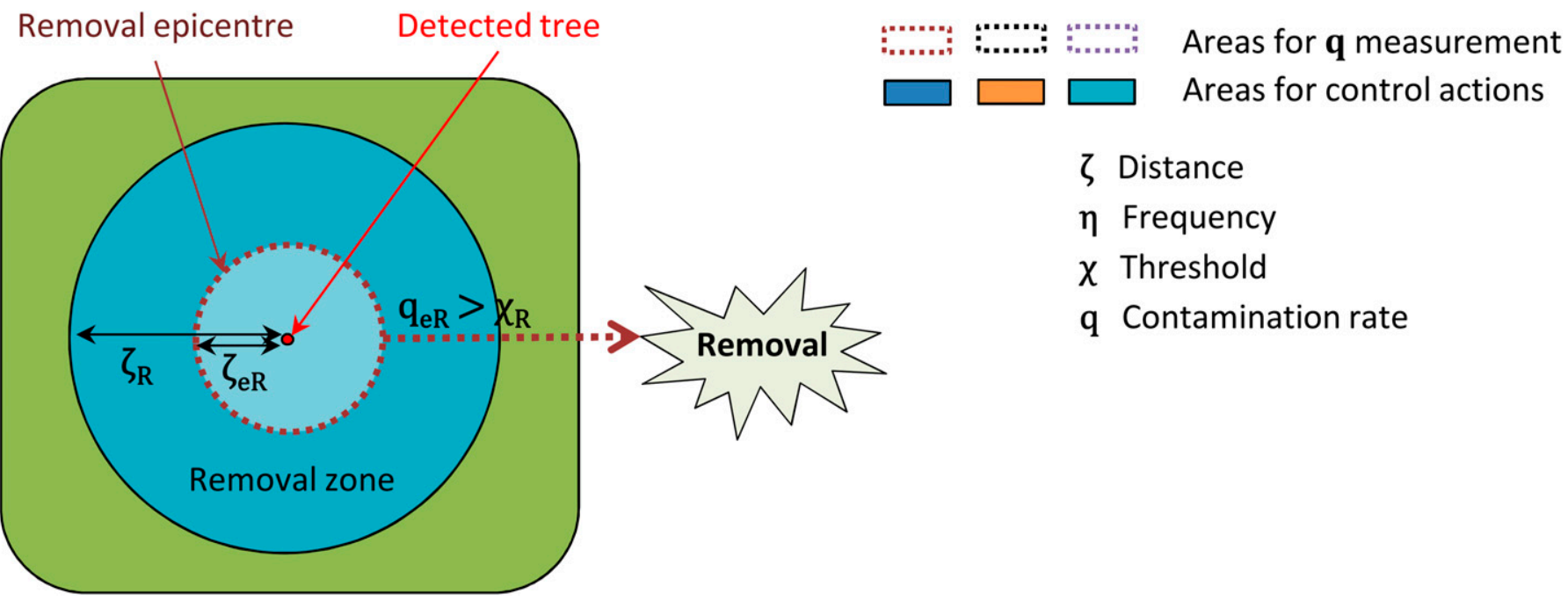

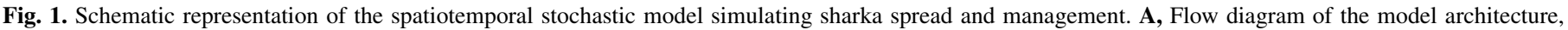

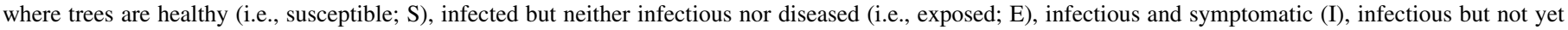

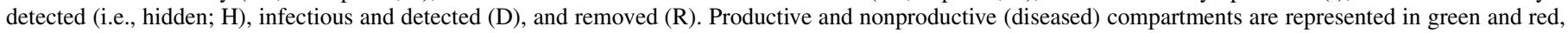

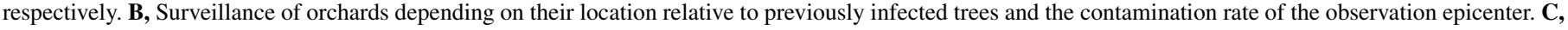

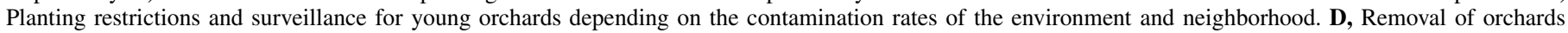

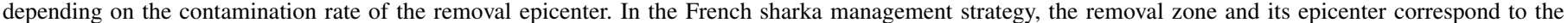
orchard only (i.e., $\zeta_{e R}=\zeta_{R}=0$ ) (Fig. 4A). All model parameters are defined in the text and listed in Table 1 . 
Additionally, young orchards are surveyed $\eta_{y}$ times per year during $\gamma_{y}$ years, but this frequency is changed to $\eta_{y *}$ if, the year before orchard planting, the contamination rate of the environment around the patch to be planted exceeds a threshold value $\chi_{y *}$ (Fig. 1C). The environment is a zone around the patch to be planted; its radius is $\zeta_{e O}$ (i.e., the same as the observation epicenter).

When different surveillance frequencies are assigned to a single orchard (e.g., because it is young and located at the intersection of focal and security zones defined around different contaminated orchards), the maximum of these surveillance frequencies is applied. Surveillance dates are drawn from a uniform distribution between the 92th and the 207th day of the year (i.e., the earliest and the latest surveillance dates in the database collected in southeastern France, respectively). If the cultivar produces flowers with petals (on which symptoms may be observed), the surveillance period is extended from the 59th to the 207th day.

Removals and replanting. Detected trees are removed individually and are not supposed to be replanted, because it would lead to orchard desynchronization in terms of phenology and fruit maturation. However, to avoid excessive fragmentation of orchards owing to individual removals, orchards are totally removed if the proportion of living trees (i.e., trees in states S, E, H, and D) falls below $\chi_{S E H D}$, which is a threshold for economic profitability. Moreover, detected trees trigger the definition of two nested zones (unrelated to the observation zones) around their orchard: all orchards in the removal zone (with a radius of $\zeta_{R}$ ) must be removed if the contamination rate $q_{e R}$ of a removal epicenter (nested within the removal zone and defined by a radius $\zeta_{e R}<\zeta_{R}$ ) exceeds a threshold value $\chi_{R}$ (Fig. 1D). Two Boolean parameters, $Y_{R}{ }^{T}$ and $Y_{R}$, indicate whether individual detected trees or whole orchards, respectively, are to be removed after a mean delay of $\delta$ or at the end of the year. Orchards can be replanted after a delay of $\gamma_{S}$ years. However, planting is forbidden if the contamination rate of the environment exceeds a threshold value $\chi_{\bar{y}}\left(\chi_{y *}<\chi_{\bar{y}}\right)$ or if an orchard located at a distance below $\zeta_{n}$ (this radius defines a zone called "neighborhood") has a contamination rate above a threshold $\chi_{n}$ (Fig. 1C).

Output variables. The model computes two output variables: the net present value (NPV; in euros) of prunus cultivation and the equivalent number of fully productive trees per hectare and per year $(Y)$. The former is used as an economic optimization criterion in our approach based on sensitivity analyses. Specifically designed for this work, it is computed from the first $\left(a_{m}=6\right)$ to the last $\left(a_{f}=35\right)$ year of sharka management. Considering the whole production area as a single "farm" with all of the benefits and costs associated with prunus cultivation and sharka management, for year $a\left(a=a_{m}, \ldots\right.$, $a_{f}$ ), the gross margin (noted $G M_{a}$ ) of this farm can be calculated as the benefit generated by fruit sales ( $p$; in euros per hectare) minus fruit harvest costs $\left(c_{H}\right.$; in euros per hectare), fixed cultivation costs $\left(c_{F}\right.$; in euros per hectare), orchard planting cost $\left(c_{S}\right.$; in euros per hectare), orchard observation cost ( $c_{O}$; in euros per hectare), and the cost of removal of a tree $\left(c_{R}{ }^{T}\right.$; in euros per hectare) or a whole orchard $\left(c_{R}\right.$; in euros per hectare). Reference values for these economic parameters were estimated (details are in Supplementary Table S1) based on expert opinions (i.e., professional organizations in charge of sharka management in France) as well as data on French peach production (Agreste 2013, 2014, 2015), selling price (FranceAgriMer 2015), and consumer price index (INSEE 2015). The cost of one orchard observation $\left(c_{O}\right)$ is described by a simple linear function of the detection probability: $c_{O}=40+182 \times \rho$. This function is calibrated via expert opinions considering a fixed cost of access to the patch and a surveillance cost proportional to the detection effort. This last feature allows us to account for the effect of a partial surveillance of orchards (e.g., every other row only), which reduces both the average detection probability $(\rho)$ and the observation cost. Thus, for all orchards $i(i \in\{1, \ldots, I\})$ of the production area during year $a, G M_{a}$ is calculated as follows:

$$
\begin{aligned}
G M_{a}= & \sum_{i=1}^{I}\left\{y_{i, a} \cdot\left(p-c_{H}\right) \cdot \frac{S_{i, a}+E_{i, a}}{N_{i, a}} \cdot A_{i}-c_{F} \cdot A_{i}-1_{i, a}^{R} \cdot c_{R} \cdot A_{i}\right. \\
& \left.-1_{i, a}^{S} \cdot c_{S} \cdot A_{i}-c_{R}^{T} \cdot R_{i, a}^{+}-\mathrm{c}_{\mathrm{o}} \cdot O_{i, a} \cdot A_{i}\right\}
\end{aligned}
$$

with

$y_{i, a}$ : the relative fruit yield of nondiseased trees depending on their age (Table 1);

$A_{i}$ : the orchard area (hectares);

$\frac{S_{i, a}+E_{i, a}}{N_{i, a}}$ : the proportion of the orchard that is not impacted by the disease;

$O_{i, a}:$ the number of observations within the orchard;

$R_{i, a}^{+}$: the number of newly (individually) removed trees owing to PPV detection;

$1_{i, a}^{R}$ : a Boolean that equals one if the orchard is removed and zero otherwise;

$1_{i, a}^{S}$ : a Boolean that equals one if the orchard is planted and zero otherwise.

Using a discount rate $\tau=4 \%$ (Quinet 2013), the $N P V$ for the whole production area over years $a_{m}=6$ to $a_{f}=35$ is

$$
N P V=\sum_{a=a_{m}}^{a_{f}} \frac{G M_{a}}{(1+\tau)^{\left(a-a_{m}\right)}}
$$

The equivalent number of fully productive trees $(Y)$ was used to assess the epidemiological performance of management strategies that were economically improved using the $N P V$. This criterion was defined previously (Rimbaud et al. 2018a) by

$$
Y=\frac{1}{\left(a_{f}-a_{m}+1\right) \sum_{i=1}^{I} A_{i}} \sum_{a=a_{m}}^{a_{f}} \sum_{i=1}^{I}\left\{y_{i, a} \cdot\left(S_{i, a}+E_{i, a}\right)\right\}
$$

In this criterion, fully productive trees (i.e., mature and healthy) count as one, whereas diseased and newly planted trees (juvenile) count as zero.

Management improvement through sequential sensitivity analyses. Improvement of the management strategy was performed using three sensitivity analyses. For these analyses, we used Sobol's method, which is a reference method to compute sensitivity indices of model parameters and their interactions (Saltelli et al. 2008; Sobol 1993). Each sensitivity analysis consists of (i) defining the target parameters, their respective variation ranges, and probability distributions (uniform; in this work); (ii) generating a design to explore the parameter space (using Sobol's sequences in this work) (details are in Rimbaud et al. 2018a); (iii) running simulations; and (iv) computing Sobol's sensitivity indices, which quantify the influence of the variation of each target parameter on the output variable. Let $Y$ denote the output variable, and $X_{i}(i=1, \ldots, p)$ denote the input parameters of the model. Sobol's indices are calculated for each $X_{i}$ as follows:

$$
\begin{aligned}
S I_{1}^{X_{i}} & =\frac{\operatorname{Var}\left[E\left(Y \mid X_{i}\right)\right]}{\operatorname{Var}(Y)} \\
S I_{\text {tot }}^{X_{i}} & =\frac{E\left[\operatorname{Var}\left(Y \mid X_{-i}\right)\right]}{\operatorname{Var}(Y)}
\end{aligned}
$$

where $X_{-i}$ denotes the whole set of parameters except for $X_{i} . S I_{1}^{X_{i}}$ is the first-order index, which measures the main effect of $X_{i}$ alone, and $S I_{\text {tot }}^{X_{i}}$ is the total index, which measures the influence of $X_{i}$, including all of its interactions with other parameters. These dimensionless indices are bounded by zero and one, and a total index close to zero means that the variation of the parameter has a negligible effect on the output variable. 
To enable comparison among the sensitivity indices of the model parameters, Sobol's method requires to sample the target parameters from independent distributions. Thus, because the focal zone (radius $\left.\zeta_{f}\right)$, the observation epicenter $\left(\zeta_{e O}\right)$, and the removal epicenter $\left(\zeta_{e R}\right)$ are contained within the security zone $\left(\zeta_{s}\right)$, the focal zone $\left(\zeta_{f}\right)$, and the removal zone $\left(\zeta_{R}\right)$, respectively, these zones were reparameterized using the following area ratios (bounded by zero and one):

$$
r_{\zeta_{f}}=\frac{\pi \times \zeta_{f}^{2}}{\pi \times \zeta_{s}^{2}}=\left(\frac{\zeta_{f}}{\zeta_{s}}\right)^{2}, r_{\zeta_{e O}}=\left(\frac{\zeta_{e O}}{\zeta_{f}}\right)^{2}, \text { and } r_{\zeta_{e R}}=\left(\frac{\zeta_{e R}}{\zeta_{R}}\right)^{2}
$$

In addition, the contamination threshold above which surveillance frequency in young orchards is modified $\left(\chi_{y *}\right)$ was reparameterized using its ratio relative to the contamination threshold above which replanting is forbidden $\left(\chi_{\bar{y}}\right): r_{\chi_{y^{*}}}=\frac{\chi_{y^{*}}}{\chi_{\bar{y}}}$.

Step 1: Assessing the relative influence of model parameters. The 23 control parameters defined in the implemented management strategy were targeted in this first step in addition to six parameters associated with the main epidemiological processes (introduction: $q_{\kappa}, \Phi$, and $p_{M I}$; dispersal: $W_{\text {exp }}$; transmission coefficient: $\beta$; and latent period duration: $\theta_{\text {exp }}$ ). Except for $q_{\kappa}$ (connectivity of the patch

TABLE 1. Model parameters: description, reference values for sharka epidemics in French peach orchards, and variation ranges in the sensitivity analyses ${ }^{\mathrm{a}}$

\begin{tabular}{|c|c|c|c|c|c|c|}
\hline \multirow[b]{2}{*}{ Parameter } & \multirow[b]{2}{*}{ Description } & \multirow[b]{2}{*}{ Reference value } & \multicolumn{2}{|c|}{ Steps 1 and 2} & \multicolumn{2}{|c|}{ Step 3} \\
\hline & & & Minimum & Maximum & Minimum & Maximum \\
\hline \multicolumn{7}{|c|}{$\begin{array}{l}\text { Temporal and landscape } \\
\text { parameters }\end{array}$} \\
\hline$a_{m}$ & First year of management & 6 & - & - & - & - \\
\hline$a_{f}$ & Last year of simulation & 35 & - & - & - & - \\
\hline$\psi$ & Expected orchard duration (years) & $15^{b}$ & - & - & - & - \\
\hline \multicolumn{7}{|c|}{ Epidemiological parameters } \\
\hline$q_{\kappa}$ & $\begin{array}{l}\text { Quantile of the connectivity of the patch } \\
\text { of first introduction }\end{array}$ & 0.50 & $0.00^{\mathrm{c}}$ & $1.00^{\mathrm{c}}$ & - & - \\
\hline$\phi$ & Probability of introduction at planting & $0.007^{\mathrm{b}}$ & $0.0046^{\mathrm{d}}$ & $0.0107^{\mathrm{d}}$ & - & - \\
\hline$p_{M I}$ & $\begin{array}{l}\text { Relative probability of massive } \\
\text { introduction }\end{array}$ & $0^{\mathrm{b}}$ & $0.00^{\mathrm{b}}$ & $0.10^{\mathrm{b}}$ & - & - \\
\hline$W_{\text {exp }}$ & Expected value of the dispersal variable & $0.486^{\mathrm{d}}$ & $0.469^{\mathrm{d}}$ & $0.504^{\mathrm{d}}$ & - & - \\
\hline$W_{\text {var }}$ & Variance of the dispersal variable & $0.0434^{\mathrm{d}}$ & - & - & - & - \\
\hline$\beta$ & Transmission coefficient & $1.32^{\mathrm{d}}$ & $1.25^{\mathrm{d}}$ & $1.39^{\mathrm{d}}$ & - & - \\
\hline$\theta_{\text {exp }}$ & $\begin{array}{l}\text { Expected duration of the latent period } \\
\text { (years) }\end{array}$ & $1.92^{\mathrm{d}}$ & $1.71^{\mathrm{d}}$ & $2.14^{\mathrm{d}}$ & - & - \\
\hline$\theta_{\text {var }}$ & $\begin{array}{l}\text { Variance of the latent period duration } \\
\left(\text { years }^{2}\right)\end{array}$ & $0.44^{\mathrm{d}}$ & - & - & - & - \\
\hline \multicolumn{7}{|c|}{ Surveillance parameters } \\
\hline$\rho$ & $\begin{array}{l}\text { Probability of detection of a symptomatic } \\
\text { tree }\end{array}$ & $0.66^{\mathrm{d}}$ & $\mathbf{0}^{\mathrm{c}}$ & $0.66^{\mathrm{e}}$ & 0.2 & 0.66 \\
\hline$\gamma_{o}$ & Duration of surveillance zones (years) & $3^{\mathrm{f}}$ & $\mathbf{0}^{\mathrm{c}}$ & $10^{\mathrm{g}}$ & $\mathbf{0}$ & 10 \\
\hline$\gamma_{y}$ & Duration of young orchards (years) & $3^{\mathrm{f}}$ & $\mathbf{0}^{\mathrm{c}}$ & $10^{\mathrm{g}}$ & $\mathbf{0}$ & 3 \\
\hline$\zeta_{s}$ & Radius of security zones (m) & $2,500^{\mathrm{f}}$ & $\mathbf{0}^{\mathrm{c}}$ & $\mathbf{5 , 8 0 0}{ }^{\mathrm{h}}$ & $\mathbf{0}$ & 1,000 \\
\hline$r_{\zeta_{f}}$ & $\begin{array}{l}\text { Ratio of the focal area over the security } \\
\text { area }\end{array}$ & $0.36^{\mathrm{f}}$ & $\mathbf{0}^{\mathrm{c}}$ & $\mathbf{1}^{\mathrm{c}}$ & - & - \\
\hline$r_{\zeta_{e O}}$ & $\begin{array}{l}\text { Ratio of the observation epicenter area } \\
\text { over the focal area }\end{array}$ & $0.14^{\mathrm{f}}$ & $0^{\mathrm{c}}$ & $1^{\mathrm{c}}$ & - & - \\
\hline $1 / \eta_{O}$ & $\begin{array}{l}\text { Maximal period between two observations } \\
\text { (years) }\end{array}$ & $6^{\mathrm{f}}$ & $\mathbf{1}^{\mathrm{c}}$ & $15^{\mathrm{i}}$ & 1 & 15 \\
\hline$\eta_{s}$ & $\begin{array}{l}\text { Surveillance frequency in security zones } \\
\left(\text { year }^{-1}\right)\end{array}$ & $1^{\mathrm{f}}$ & $\mathbf{0}^{\mathrm{c}}$ & $\mathbf{8}^{\mathrm{j}}$ & $\mathbf{0}$ & 4 \\
\hline$\eta_{f}$ & $\begin{array}{l}\text { Surveillance frequency in focal zones } \\
\left(\text { year }^{-1}\right)\end{array}$ & $2^{\mathrm{f}}$ & $\mathbf{0}^{\mathrm{c}}$ & $8^{\mathrm{j}}$ & - & - \\
\hline$\eta_{f^{*}}$ & Modified surveillance frequency in focal & $3^{\mathrm{f}}$ & $0^{\mathrm{c}}$ & $8^{\mathrm{j}}$ & - & - \\
\hline
\end{tabular}

(Continued on next page)

a The first sensitivity analysis (step 1) targeted 23 control parameters and 6 epidemiological parameters to assess their relative influence on model outputs. In the second step, only the 17 most influential control parameters (bounds in bold) were kept and improved. In the third step, 6 unnecessary parameters were removed, 1 parameter was fixed, and the remaining 10 parameters (in bold) were further improved. In the second and third steps, the epidemiological parameters were not targeted in the sensitivity analysis, but for each simulated epidemic, they were drawn from a uniform distribution within the variation range used in the first step.

${ }^{\mathrm{b}}$ Estimated through expert opinion (i.e., professional organizations in charge of sharka management in France).

c Mathematical domain of definition.

d Estimated in Pleydell et al. (2018).

e We assumed that the detection probability could not be higher because of technical limitations.

${ }^{\mathrm{f}}$ Fixed by JORF (2011). With regard to $\zeta_{R}$ and $\mathrm{r}_{\zeta_{\text {e }}}$, when fixed at zero, the removal zone or the removal epicenter corresponds to the contaminated orchard only.

$\mathrm{g}$ These durations aim to detect latent infections, and the duration of 10 years is well beyond the expected duration of the latent period $\left(\theta_{\text {exp }}\right)$.

$\mathrm{h}$ The maximal distance between the centroids of two orchards in the landscape is 5,800 $\mathrm{m} ; 5,475 \mathrm{~m}$ is the maximal distance between the closest points of two orchards.

i The expected duration $(\psi)$ of an orchard is 15 years.

j Given the time window to survey prunus leaves in orchards, eight observations per year are equivalent to one observation per fortnight. We supposed that higher surveillance frequencies were not economically viable, which has been confirmed by the results of the sensitivity analyses.

${ }^{k}$ Either zero or one (Boolean parameter).

${ }^{1}$ In the model, the management process does not change any more for $\chi_{R}>0.34$, because any orchard with a proportion below $\chi_{S E H D}=0.66$ of living trees is removed for profitability reasons.

${ }^{\mathrm{m}}$ With $\rho=0.66$.

${ }^{\mathrm{n}}$ Estimated from the economic analysis of prunus cultivation.

${ }^{\circ}$ Quinet 2013. 
of first introduction) and $p_{M I}$ (probability of massive introduction), variation ranges of the epidemiological parameters were defined as the $99 \%$ credibility intervals of the estimates provided by a Bayesian inference model applied to epidemics of the $M$ strain of PPV in southeastern France (Pleydell et al. 2018). In contrast, variation ranges of $q_{\kappa}, p_{M I}$, and the 23 control parameters were informed by expert opinions and restricted to realistic values with respect to sharka epidemics and management (Table 1).

Simulations were performed for 310,155 different parameter combinations generated with Sobol's sequences (Sobol 1976). To account for stochasticity (e.g., Rimbaud et al. 2018a), each combination was replicated 30 times (this number, above which the total computational time would be prohibitive, was sufficient to obtain robust estimates of the mean and standard deviation associated with each combination) (Supplementary Fig. S1). Then, the indices were calculated as in Rimbaud et al. (2018a) to assess the influence of target parameters on the means and standard deviations of the economic ( $\mu_{N P V}$ and $\sigma_{N P V}$, respectively) and epidemiological ( $\mu_{Y}$ and $\sigma_{Y}$, respectively) criteria.

Step 2: Approximating optimal values of the most influential parameters. In the second step, only the most influential control parameters (i.e., those with the highest $S I_{\text {tot }}$ ) identified in the first step were retained (Results). The six least influential control parameters were removed from the model, and the 17 remaining

TABLE 1. (Continued from previous page)

\begin{tabular}{|c|c|c|c|c|c|c|}
\hline \multirow[b]{2}{*}{ Parameter } & \multirow[b]{2}{*}{ Description } & \multirow[b]{2}{*}{ Reference value } & \multicolumn{2}{|c|}{ Steps 1 and 2} & \multicolumn{2}{|c|}{ Step 3} \\
\hline & & & Minimum & Maximum & Minimum & Maximum \\
\hline$\eta_{y}$ & $\begin{array}{l}\text { Surveillance frequency in young orchards } \\
\left(\text { year }^{-1}\right)\end{array}$ & $2^{f}$ & $\mathbf{0}^{\mathrm{c}}$ & $\mathbf{8}^{\mathrm{j}}$ & $\mathbf{0}$ & 2 \\
\hline$\eta_{y *}$ & $\begin{array}{l}\text { Modified surveillance frequency in young } \\
\text { orchards }\left(\text { year }^{-1}\right)\end{array}$ & $3^{\mathrm{f}}$ & $0^{c}$ & $8^{\mathrm{j}}$ & - & - \\
\hline$\chi_{o}$ & $\begin{array}{l}\text { Contamination threshold in the } \\
\text { observation epicenter, above which } \\
\text { surveillance frequency in the focal zone } \\
\text { is modified }\end{array}$ & $0.02^{\mathrm{f}}$ & $0^{\mathrm{c}}$ & $1^{\mathrm{c}}$ & - & - \\
\hline$r_{\chi_{y^{*}}}$ & $\begin{array}{l}\text { Ratio (over } \chi_{\bar{y}} \text { ) of the contamination } \\
\text { threshold in the environment, above } \\
\text { which surveillance frequency in young } \\
\text { orchards is modified }\end{array}$ & $0.50^{\mathrm{f}}$ & $0^{\mathrm{c}}$ & $1^{\mathrm{c}}$ & - & - \\
\hline \multicolumn{7}{|c|}{ Removal parameters } \\
\hline$\delta$ & $\begin{array}{l}\text { Mean delay before removal of a detected } \\
\text { tree (days) }\end{array}$ & $10^{\mathrm{f}}$ & - & - & - & - \\
\hline$Y_{R}^{T}$ & $\begin{array}{l}\text { (Boolean) individual trees are removed: } 0 \text { : } \\
\text { after a mean delay } \delta ; 1 \text { : at the end of the } \\
\text { year }\end{array}$ & $0^{\mathrm{f}}$ & $\mathbf{0}^{\mathrm{c}, \mathrm{k}}$ & $\mathbf{1}^{\mathrm{c}, \mathrm{k}}$ & 0 & 0 \\
\hline$Y_{R}$ & $\begin{array}{l}\text { (Boolean) whole orchards are removed: } 0 \text { : } \\
\text { after a mean delay } \delta ; 1: \text { at the end of the } \\
\text { year }\end{array}$ & $1^{\mathrm{f}}$ & $\mathbf{0}^{\mathrm{c}, \mathrm{k}}$ & $\mathbf{1}^{\mathrm{c}, \mathrm{k}}$ & - & - \\
\hline$\zeta_{R}$ & Radius of the removal zone $(\mathrm{m})$ & $0^{\mathrm{f}}$ & $\mathbf{0}^{\mathrm{c}}$ & $\mathbf{5 , 8 0 0}{ }^{\mathrm{h}}$ & - & - \\
\hline$r_{\zeta_{e R}}$ & $\begin{array}{l}\text { Ratio of the removal epicenter area over } \\
\text { the removal area }\end{array}$ & $0^{\mathrm{f}}$ & $\mathbf{0}^{\mathrm{c}}$ & $\mathbf{1}^{\mathrm{c}}$ & - & - \\
\hline$\chi_{R}$ & $\begin{array}{l}\text { Contamination threshold in the removal } \\
\text { epicenter, above which orchards inside } \\
\text { the removal zone are removed }\end{array}$ & $0.10^{f}$ & $\mathbf{0}^{\mathrm{c}}$ & $0.34^{1}$ & - & - \\
\hline \multicolumn{7}{|c|}{ Replanting parameters } \\
\hline$\gamma_{S}$ & $\begin{array}{l}\text { Delay before replanting a removed } \\
\text { orchard (years) }\end{array}$ & $0^{f}$ & $\mathbf{0}^{\mathrm{c}}$ & $10^{\mathrm{g}}$ & $\mathbf{0}$ & 7 \\
\hline$\zeta_{n}$ & Radius of the neighborhood (m) & $200^{f}$ & $\mathbf{0}^{\mathrm{c}}$ & $5,475^{\mathrm{h}}$ & $\mathbf{0}$ & 5,475 \\
\hline$\chi_{\bar{y}}$ & $\begin{array}{l}\text { Contamination threshold in the } \\
\text { environment around young orchards, } \\
\text { above which the planting of orchards is } \\
\text { forbidden }\end{array}$ & $0.02^{\mathrm{f}}$ & $0^{c}$ & $1^{\mathrm{c}}$ & - & - \\
\hline$\chi_{n}$ & $\begin{array}{l}\text { Contamination threshold in the } \\
\text { neighborhood, above which the planting } \\
\text { of orchards is forbidden }\end{array}$ & $0.05^{\mathrm{f}}$ & $\mathbf{0}^{\mathrm{c}}$ & $\mathbf{1}^{\mathrm{c}}$ & 0.2 & 1 \\
\hline \multicolumn{7}{|c|}{ Economic parameters } \\
\hline$y$ & $\begin{array}{l}\text { Relative age-dependent yield of hosts in S } \\
\text { or E states }\end{array}$ & $\begin{array}{l}0.00 \text { until } 2 \text { years }^{\mathrm{b}} \\
0.50 \text { at } 3 \text { years }{ }^{\mathrm{b}} \\
0.65 \text { at } 4 \text { years }^{\mathrm{b}} \\
0.85 \text { at } 5 \text { years }{ }^{\mathrm{b}} \\
1.0 \text { from } 6 \text { to } 15 \text { years }^{\mathrm{b}} \\
0.80{\text { from } 16 \text { years }^{\mathrm{b}}}\end{array}$ & - & - & - & - \\
\hline$c_{S}$ & Planting cost of one orchard $\left(€ \cdot \mathrm{ha}^{-1}\right)$ & $14,000^{\mathrm{b}}$ & - & - & - & - \\
\hline$c_{O}$ & Cost of one observation $\left(€ \cdot \mathrm{ha}^{-1}\right)$ & $160^{\mathrm{b}, \mathrm{m}}$ & - & - & - & - \\
\hline$c_{R}^{T}$ & Removal cost of one individual tree $(€)$ & $15^{\mathrm{b}}$ & - & - & - & - \\
\hline$c_{R}$ & Removal cost of one orchard $\left(€ \cdot \mathrm{ha}^{-1}\right)$ & $1,000^{\mathrm{b}}$ & - & - & - & - \\
\hline$c_{H}$ & Yearly harvest cost $\left(€ \cdot\right.$ ha $\left.^{-1}\right)$ & $16,500^{\mathrm{b}}$ & & & & \\
\hline$c_{F}$ & $\begin{array}{l}\text { Yearly fixed cost associated with } \\
\text { prunus cultivation }\left(€ \cdot \mathrm{ha}^{-1}\right)\end{array}$ & $13,600^{\mathrm{n}}$ & - & - & - & - \\
\hline$p$ & $\begin{array}{l}\text { Maximal yearly benefit generated by } \\
\text { fruit harvest }\left(€ \cdot \text { ha }^{-1}\right)\end{array}$ & $37,250^{\mathrm{n}}$ & - & - & - & - \\
\hline$\tau$ & Discount rate & $0.04^{\circ}$ & - & - & - & - \\
\hline$\chi_{S E H D}$ & $\begin{array}{l}\text { Minimum proportion of living trees, } \\
\text { below which the orchard is not } \\
\text { profitable and thus, removed }\end{array}$ & $0.66^{n}$ & - & - & - & - \\
\hline
\end{tabular}


parameters were varied within the same variation ranges as previously done (Table 1) using 310,156 different parameter combinations and 30 stochastic replicates. In this sensitivity analysis, the six epidemiological parameters were not targeted, but for each simulation, they were drawn from uniform distributions using the same bounds as in the previous step to optimize the management strategy for variable (but realistic) epidemics.

The optimal values of the 17 control parameters were jointly approximated by identifying the parameter combination associated with the highest $\mu_{N P V}$ ("best-value strategy"). To identify alternative improved strategies, a marginal approximation of the same parameters was also performed using the mode of the distribution of each parameter within the combinations associated with the best $1 \%$ values of $\mu_{N P V}$ ("best-percent strategy"). A similar approach allowed identification of the parameters associated with the worst $1 \%$ values of $\mu_{N P V}$. The marginal approximation (performed parameter by parameter) does not account for possible interactions between parameters, contrary to the first method that retains a whole parameter combination.

Step 3: Improving the approximate optimal values. Based on the results of the previous step, six control parameters were found unnecessary (Results) and subsequently removed from the model. One control parameter had the same value for all strategies with the best $N P V \mathrm{~s}$, and it was thus fixed at this value. The optimal values of the 10 remaining control parameters were still very imprecise; thus, these 10 parameters were further improved using a dedicated sensitivity analysis with variation ranges restricted to the intervals where most of the best $1 \%$ values of $\mu_{N P V}$ were found in step 2 (Table 1). This sensitivity analysis was performed as in previous steps using 310,152 different parameter combinations and 30 replicates. For each simulated epidemic, the epidemiological parameters were drawn from uniform distributions as in step 2.

Simulation of the improved management strategies. To test the performance of the identified management strategies, 10,000 simulation replicates were performed with parameters corresponding to different scenarios: (A) "disease free" (PPV is not introduced in the landscape), (B) "management free" (PPV is introduced and is not managed), (C) "reference management" (PPV is introduced and managed according to the current French strategy) (Table 1). (D) best-value strategy, and (E) best-percent strategy (Table 2). In scenarios B to E, the six epidemiological parameters were drawn from uniform distributions within their respective variation ranges (Table 1). The impact of the epidemic was assessed using the distribution of the epidemiological criterion $(Y)$ and the economic criterion $(N P V)$ as well as the dynamics of annual prevalence and incidence and the dynamics of observations and removals.

Furthermore, the robustness of the identified management strategies to harsher epidemic contexts was tested using similar simulations with either doubled values for the pathogen transmission coefficient $(\beta)$ or halved values for the latent period duration $\left(\theta_{\text {exp }}\right)$. New strategies, specifically improved for each context, were identified by following the three steps of our heuristic approach.

Computing tools. The model was written in $\mathrm{R}$ and $\mathrm{C}$ languages; one simulation takes around $8 \mathrm{~s}$ on an Intel Core i7-4600M computer. Within the R software v3.0.3 (R Core Team 2012), Sobol's sequences were generated, and Sobol's indices were calculated using the packages fOptions v3010.83 (Wuertz et al. 2017) and sensitivity v1.11 (Pujol et al. 2017), respectively.

\section{RESULTS}

We identified improved management strategies of sharka epidemics in three steps, each of them consisting of a sensitivity analysis of a model that jointly simulates sharka epidemics and a flexible management strategy (Supplementary Fig. S2 shows a general illustration).

Step 1: Identifying the most promising control parameters. In a first step, the most promising control measures to manage sharka were identified by ranking the control parameters by influence on the economic criterion (average $N P V$ over 30 years, $\mu_{N P V}$, measuring the discounted difference between benefits of fruit sales and costs generated by the management of all orchards of the production area). The first sensitivity analysis showed that the predicted economic impact strongly depends (positively) (Fig. 2) on the contamination threshold of the removal epicenter $\left(\chi_{R}\right.$; above which orchards in the removal zone are culled; total sensitivity index $S I_{\text {tot }}: 0.54 ; 95 \%$ confidence interval $\left[\mathrm{CI}_{95}\right]: 0.39$ to 0.65$)$ and the contamination threshold in orchards of the neighborhood of a previously culled orchard $\left(\chi_{n}\right.$; above which replanting is forbidden; $S I_{\text {tot }}: 0.36 ; \mathrm{CI}_{95}: 0.25$ to 0.45$)$. These parameters were also the main contributors to model stochasticity (Supplementary Fig. S3). Next comes the radius of the removal zone $\left(\zeta_{R} ; S I_{t o t}: 0.15 ; \mathrm{CI}_{95}: 0.08\right.$ to $0.20)$; then, a Boolean parameter indicating whether whole orchards are removed immediately or at the end of the year $\left(Y_{R} ; S I_{t o t}: 0.13\right.$; $\mathrm{CI}_{95}: 0.06$ to 0.18 ), and it is followed by the detection probability $\left(\rho ; S_{t o t}: 0.09 ; \mathrm{CI}_{95}: 0.07\right.$ to 0.12$)$ and the size of the removal

TABLE 2. Summary of the economically improved management strategies in different epidemic contexts ${ }^{\mathrm{a}}$

\begin{tabular}{|c|c|c|c|c|c|c|c|}
\hline \multirow[b]{3}{*}{ Parameters } & \multirow[b]{3}{*}{ Description } & \multicolumn{6}{|c|}{ Epidemic context and management strategy } \\
\hline & & \multicolumn{2}{|c|}{ Reference } & \multicolumn{2}{|c|}{ Shorter latency } & \multicolumn{2}{|c|}{$\begin{array}{c}\text { Stronger } \\
\text { transmission }\end{array}$} \\
\hline & & 1 & $1 \%$ & 1 & $1 \%$ & 1 & $1 \%$ \\
\hline$\rho$ & Detection probability & 0.36 & 0.60 & 0.57 & 0.62 & 0.47 & 0.61 \\
\hline$\zeta_{s}$ & Radius of security zones $(\mathrm{m})^{\mathrm{b}}$ & 61 & 54 & 54 & 60 & 27 & 45 \\
\hline$\zeta_{n}$ & Radius of neighborhood (km) & 2.8 & 1.0 & 4.6 & 0.86 & 4.2 & 0.81 \\
\hline$\chi_{n}$ & $\begin{array}{l}\text { Neighborhood contamination threshold, above which orchard planting is } \\
\text { forbidden }\end{array}$ & 0.60 & 0.92 & 0.70 & 0.92 & 0.73 & 0.93 \\
\hline $1 / \eta_{0}$ & Maximal period between two observations (years) & 4 & 4 & 4 & 3 & 1 & 2 \\
\hline$\eta_{s}$ & Observation frequency in security zones $\left(\right.$ year $\left.^{-1}\right)$ & 3 & 1 & 2 & 2 & 7 & 2 \\
\hline$\eta_{y}$ & Observation frequency in young orchards $\left(\right.$ year $\left.^{-1}\right)$ & - & 1 & 1 & - & - & 1 \\
\hline$\gamma_{o}$ & Duration of security zones (years) & 3 & 1 & 1 & 1 & 1 & 1 \\
\hline$\gamma_{y}$ & Duration of young orchards (years) & - & 1 & 1 & - & - & 1 \\
\hline$\gamma_{S}$ & Delay before replanting (years) & 0 & 0 & 1 & 1 & 3 & 1 \\
\hline$\mu_{Y}$ & Median number of productive hosts (trees ha-1 year-1) & 559 & 558 & 559 & 558 & 559 & 558 \\
\hline$\sigma_{Y}$ & Standard deviation of the number of productive hosts (trees ha year $^{-1}$ ) & 4.7 & 4.9 & 4.8 & 4.8 & 4.7 & 4.7 \\
\hline$\mu_{N P V}$ & Median net present value (million euros) & 13.7 & 13.7 & 13.7 & 13.6 & 12.7 & 13.1 \\
\hline$\sigma_{N P V}$ & Standard deviation of the net present value (million euros) & 0.70 & 0.80 & 0.79 & 0.84 & 0.73 & 0.76 \\
\hline
\end{tabular}


epicenter-where the contamination rate is measured to assess if orchards in the removal zone (with a radius $\left.\zeta_{R}\right)$ must be culled $\left(r_{\zeta_{e R}}\right.$; $S I_{t o t}: 0.09 ; \mathrm{CI}_{95}: 0.05$ to 0.12 ) (Fig. 2). The effect of each of these parameters seems to be mostly caused by interactions with other parameters, because their total Sobol's indices were much higher than their first-order indices. The importance of these interactions explains why it is difficult to predict the $N P V$ from the values of $\zeta_{R}$, $Y_{R}$, or $r_{\zeta_{e R}}$ alone (Fig. 2, Insets). The strong impact of removal and planting measures on the mean $N P V\left(\mu_{N P V}\right)$ is likely caused by excessive tree removals or orchard planting bans when the respective contamination thresholds are low $(<5 \%$ for removals and $<10 \%$ for planting bans) (Fig. 2, Insets). However, for higher thresholds, $\mu_{N P V}$ remained stable, suggesting that these parameters no longer have an effect. This may be the sign of the absence (or rarity) of high contamination events in orchards or removal epicenters (and thus, of extremely rare planting bans or removal of whole zones). Finally, the quadratic effect of $\rho$ reveals the existence of a tradeoff between detection efficiency and the costs induced by orchard surveillance.

The 11 least influential parameters (five epidemiological parameters and six control parameters) had very low total sensitivity indices $(<0.03)$, which indicate a negligible effect of their variation on the mean output. These 11 parameters included all epidemiological parameters except for the connectivity of the patch of first pathogen introduction $\left(q_{\kappa}\right)$. This suggests that, in the simulated context, the economic impact of epidemics depends more on control actions than on the epidemics themselves (except for the location of the first PPV introduction). Nevertheless, some control actions (those governed by the six least influential control parameters) also have little effect on the economic impact of epidemics. These control actions relate to the reinforcement of visual surveillance in locally highly contaminated areas $\left(r_{\zeta_{e O}}, \chi_{\mathrm{o}}\right.$, and $\eta_{f^{*}}$ ) or young orchards ( $r_{\chi_{\text {y* }}}$ and $\eta_{y^{*}}$ ) or relate to planting bans after orchard removals $\left(\chi_{\bar{y}}\right)$. The negligible influence of these control actions can be attributed to the fact that, in the simulations, the level of local contamination never reached the thresholds for surveillance reinforcement or planting ban. Similar conclusions emerged from the analysis of the epidemiological output of the model (number of fully productive trees per hectare and per year, $\mu_{Y}$ ) (Supplementary Fig. S4). Consequently, the six least influential control parameters were removed in the next step to more efficiently improve sharka management strategy.

Step 2: Approximating optimal values of control parameters. A second sensitivity analysis was performed on the control parameters only (except for the six control parameters discarded in step 1). Optimal values of the 17 control parameters were approximated by either the parameter combination leading to the best $\mu_{N P V}$ (best-value strategy) or the respective modes of the parameter distributions leading to the highest percentile of $\mu_{N P V}$ (best-percent strategy). In both approaches, management is improved when detected trees are removed immediately (i.e., after an average of 10 days rather than at the end of the year) $\left(Y_{R}^{T}\right.$ in Fig. 3). The obtained values for the removal threshold $\left(\chi_{R}\right.$; mostly $>5 \%)$, the radius of the removal zone $\left(\zeta_{R}\right.$; mostly $\left.>1,000 \mathrm{~m}\right)$, and its epicenter where the contamination rate is measured $\left(r_{\zeta_{R R}}\right.$; mostly $>0.1$ ) were so high that no removal of whole orchards may occur in the associated simulations $\left(\chi_{R}\right.$ in Fig. 3 and all other parameters in Supplementary Fig. S5). In addition, small values for

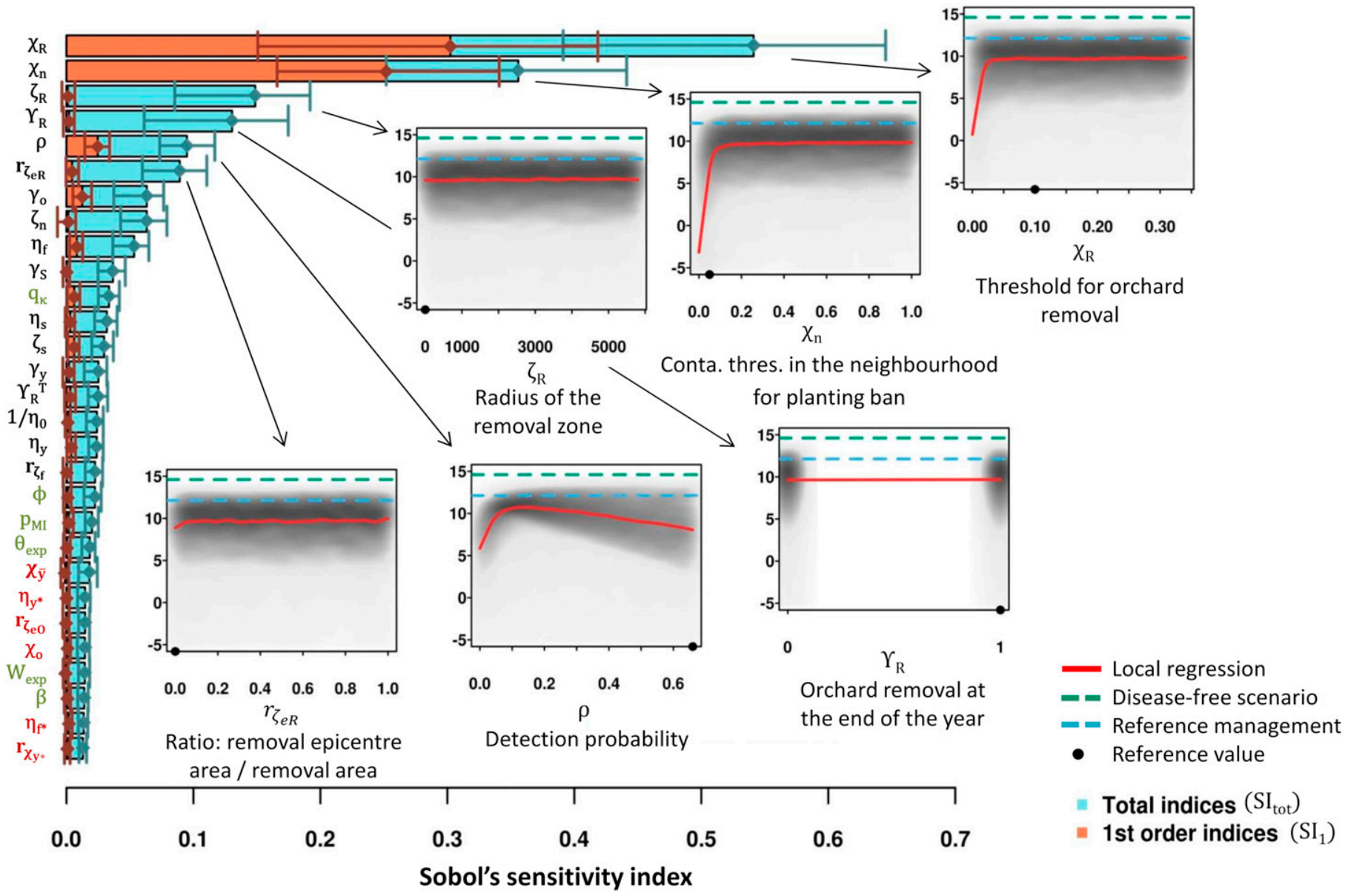

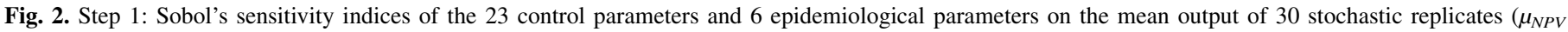

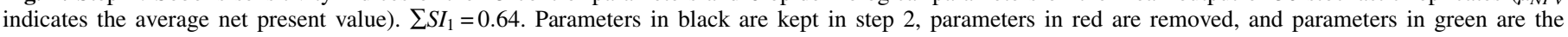

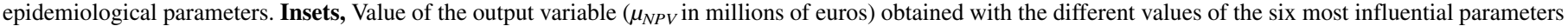
(gray background: density). All model parameters are defined in Table 1. 
these parameters $\left(\chi_{R}<5 \% ; \zeta_{R}<2 \mathrm{~km} ; r_{\zeta_{e R}}<0.2\right)$ were associated with the lowest percentile of $\mu_{N P V}$. These results suggest that, in our model, the removal of healthy hosts induces higher costs than the maintenance of undetected or latently infected hosts. Regarding surveillance, either the focal area matched approximately the security area $\left(r_{\zeta_{f}}\right.$ and $\zeta_{s}$ in the best-value strategy), or surveillance frequencies in these zones were the same $\left(\eta_{f}\right.$ and $\eta_{s}$ in the bestpercent strategy). This indicates that it may not be necessary to distinguish between focal and security zones. Thus, parameters associated with removal zones $\left(\chi_{R}, \zeta_{R}, r_{\zeta_{e R}}\right.$, and $\left.Y_{R}\right)$, and focal zones $\left(r_{\zeta_{f}}\right.$ and $\left.\eta_{f}\right)$ were discarded in the next step.

Step 3: Improving the approximation. A third sensitivity analysis was performed on the 10 remaining control parameters to further refine the approximation of their optimal value. In this analysis, variation ranges of the target parameters were restricted to the intervals where most of the best $1 \%$ values of $\mu_{N P V}$ were found in the previous step (e.g., the probability of detection $\rho$ in Fig. 3 ). Then, optimal values were approximated as in step 2 (Fig. 3 and Supplementary Fig. S6). The resulting best-value and bestpercent strategies are significantly more cost effective and simpler than the current French strategy (Fig. 4). To summarize the best-value strategy, every time that a symptomatic tree is detected in an orchard, this orchard is visually surveyed three times a year for the three

\section{Step 2}
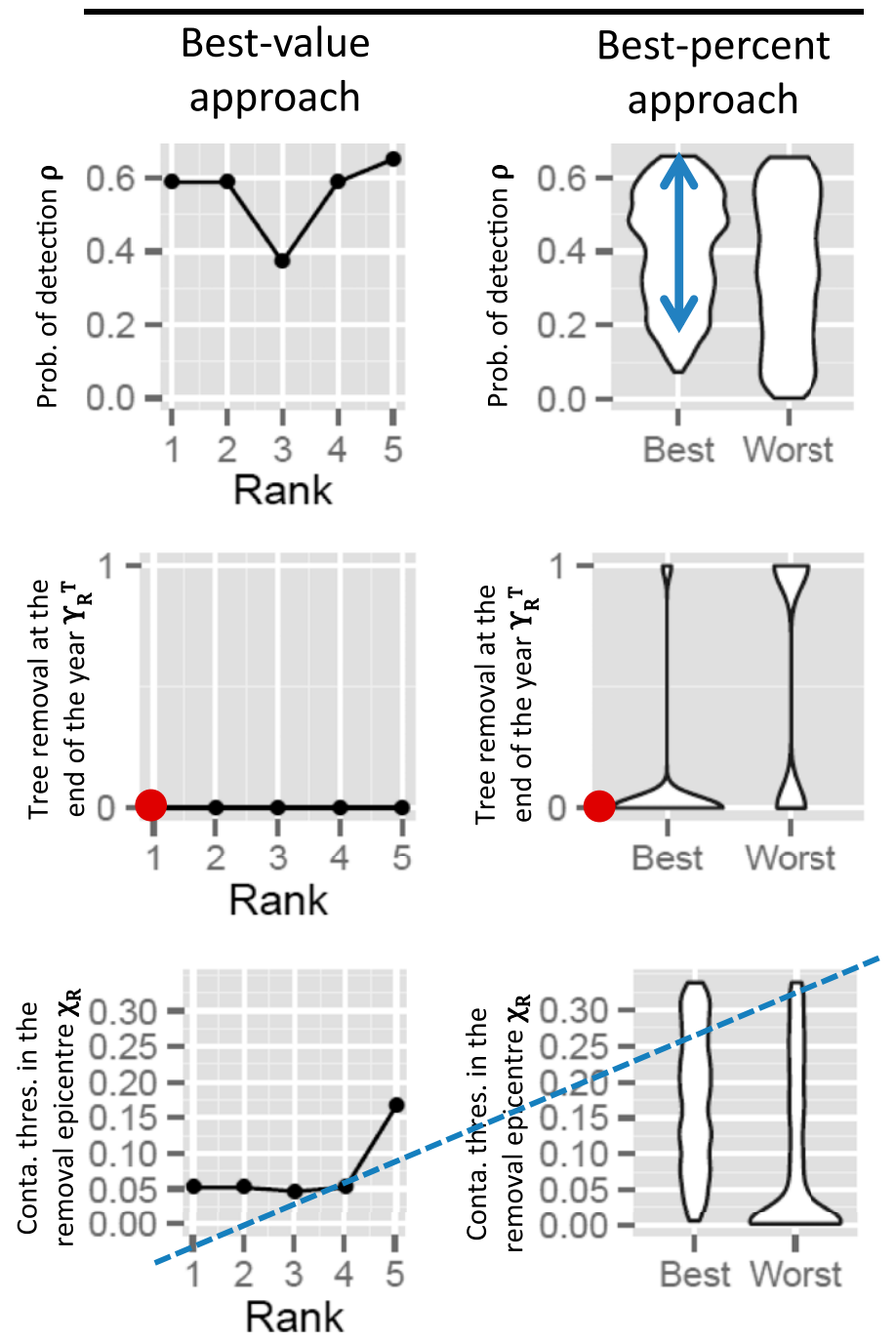

following years (Table 2, reference epidemic context). Whole orchards are removed only if the proportion of living trees falls below $\chi_{S E H D}=0.66$ (for profitability reasons), and in this case, orchards can be replanted without delay. Nevertheless, replanting is forbidden if the contamination rate of an orchard is $>60 \%$ within a radius of $2.8 \mathrm{~km}$ (i.e., in the case of a massive introduction in our simulations). In areas where no infected tree has been detected in the 3 previous years, orchards are surveyed once every 4 years. The detection probability is $36 \%$ (i.e., nearly one-half of the reference value [66\%]), which in practice, means that only every other row is surveyed in the orchards.

Alternatively, in the best-percent strategy (Table 2), each time that a symptomatic tree is detected, the corresponding orchard is surveyed once in the following year. Similar to the best-value strategy, whole orchards may only be removed for profitability reasons and can be replanted without delay (except in the unlikely event of a contamination rate $>92 \%$ in an orchard within a radius of $962 \mathrm{~m}$ ). In the first year after planting, young orchards are surveyed once. Older orchards in noncontaminated areas are routinely surveyed every 4 years. The detection probability is $60 \%$ (i.e., close to the reference value).

Simulation of the improved strategies. Repeated stochastic simulations were carried out with the identified improved strategies to compare their epidemiological $(Y)$ and economic (NPV)

\section{Step 3}

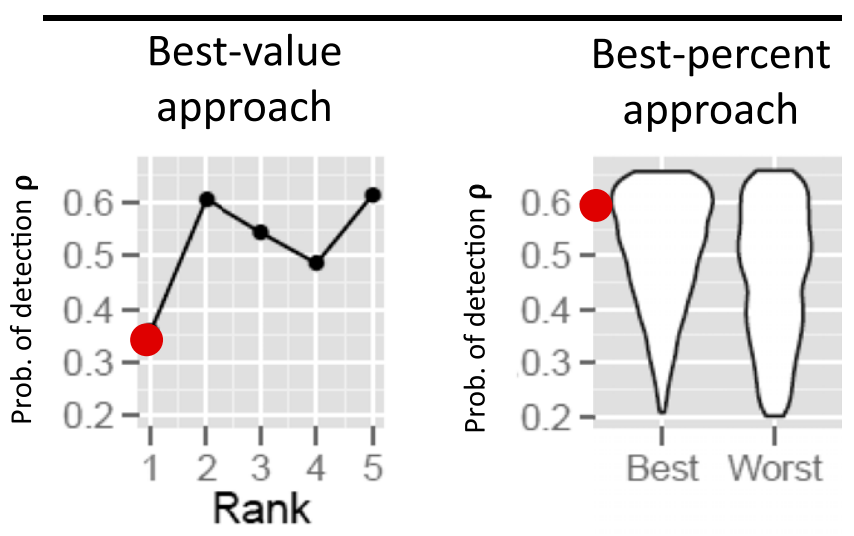

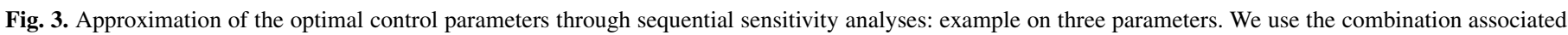

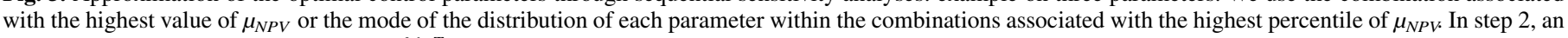

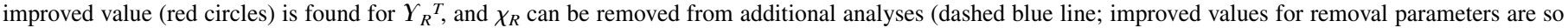
high that removals may never occur). The approximation of $\rho$ is improved in step 3 using a restricted variation range (blue arrows). 
outcomes with those obtained in disease-free and managementfree scenarios as well as with the reference management (i.e., the current strategy for managing sharka in France). These simulations show that managing the disease is vital, because the median number of productive trees per hectare and per year in the management-free scenario is only 513 and highly variable $(2.5 \%$ and $97.5 \%$ quantiles [QI $\left.{ }_{95}\right]$ : 462 and 551) compared with the disease-free scenario (median number of 560 trees; $\mathrm{QI}_{95}: 551$ and 569) (Fig. 5A). This results in a 59\% decrease in the median NPV (€6.03 million $\left[\mathrm{QI}_{95}\right.$ : -4.06 and 13.0] in the absence of management versus $€ 14.6$ million $\left[\mathrm{QI}_{95}: 13.5\right.$ and 15.7] in the absence of disease) and possibly, huge economic losses in the worst case scenarios (Fig. 5B). In our model, the reference strategy is very efficient to reduce the epidemiological impact of sharka (median of 559 productive trees per hectare and per year $\left(\mathrm{QI}_{95}\right.$ : 550 and 569). The associated $N P V\left(€ 12.1\right.$ million; $\mathrm{QI}_{95}$ : 10.7 and 13.4) is much higher than in the absence of management; however, it is $17 \%$ lower than in the disease-free scenario, indicating considerable costs of disease management. The improved best-value and best-percent strategies are nearly as efficient as the reference strategy with regard to the number of productive trees but resulted in reduced costs, with median NPVs of $€ 13.7$ million $\left(\mathrm{QI}_{95}\right.$ : 12.2 and 15.0) and $€ 13$ million $\left(\mathrm{QI}_{95}: 11.7\right.$ and 15.0), respectively. These management strategies are associated with slightly higher disease incidence and prevalence than for the current French strategy (Supplementary Fig. S7). The resulting increase in individual tree removal is overly compensated for by the smaller number of observations in orchards (Supplementary Fig. S8). Consequently, both improved strategies are more cost effective than the reference strategy.

When tested in harsher epidemiological contexts with halved expected duration of the latent period of the pathogen $\left(\theta_{\text {exp }}\right)$, the identified management strategies were still efficient with respect to both the epidemiological $(Y)$ and economic $(N P V)$ criteria (Supplementary Fig. S9). However, with doubled transmission coefficient $(\beta)$, the improved management strategies (in particular, the best-percent strategy) were not as efficient as in the reference scenario. This resulted in higher levels of disease prevalence and incidence and, consequently, more tree removals. In contrast, the reference management strategy was robust to the simulated changes in epidemic severity.

To specifically improve the management strategy in harsher epidemic contexts, we followed again all of the steps of the proposed approach. With a shorter latent period of the pathogen, the newly identified strategies mainly differ from the previous ones by the introduction of a 1-year delay before orchard replanting. This delay, which matches the mean duration of the latent period $\left(\theta_{\text {exp }}=\right.$ 0.96 year in this scenario), enables the removal of infected trees in the neighborhood before planting a new orchard (Table 2). With stronger transmission coefficient $(\beta=1.64)$, the most striking difference with the reference context is in the best-value strategy,

\section{Surveillance}

Plantings

Removals

\section{A Reference strategy observation frequency}

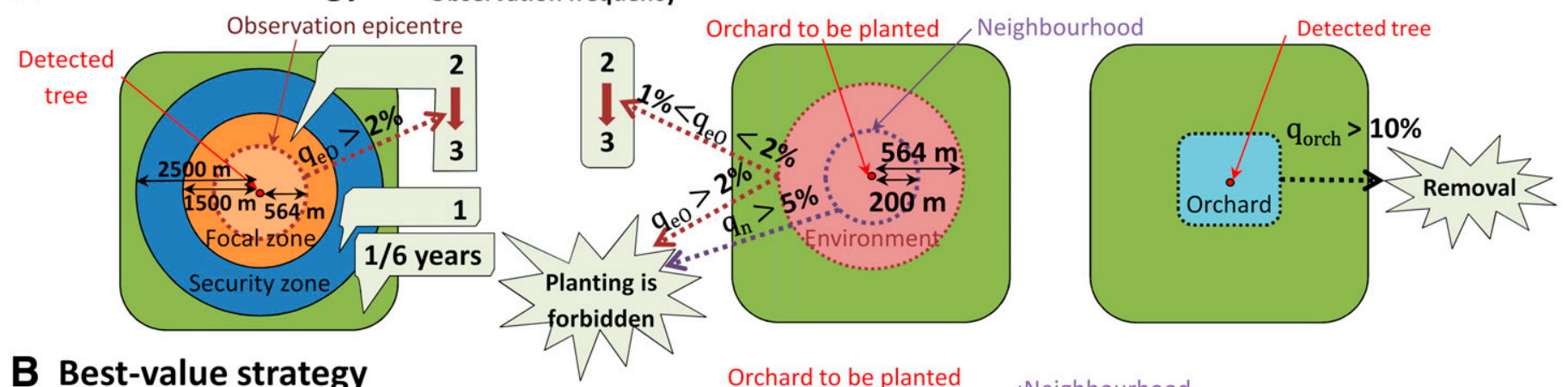

\section{B Best-value strategy}

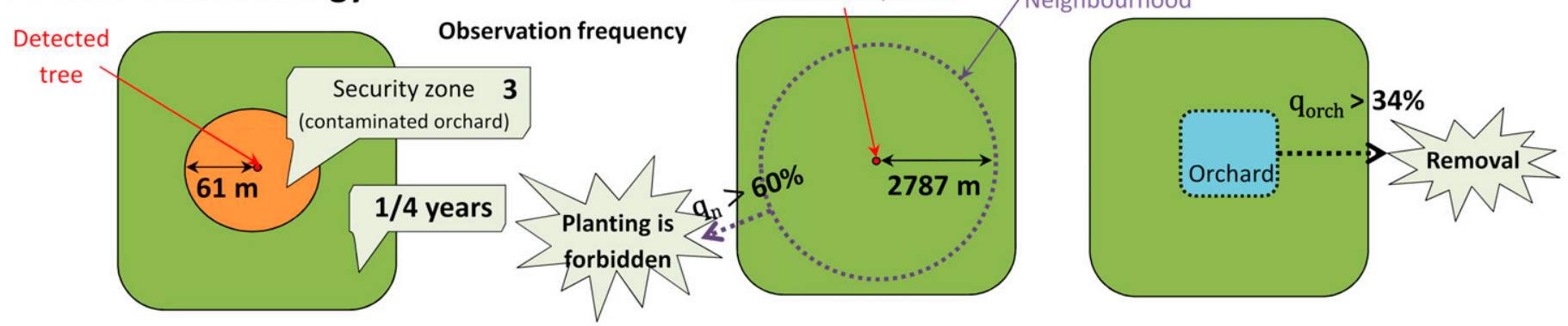

\section{Best-percent strategy}

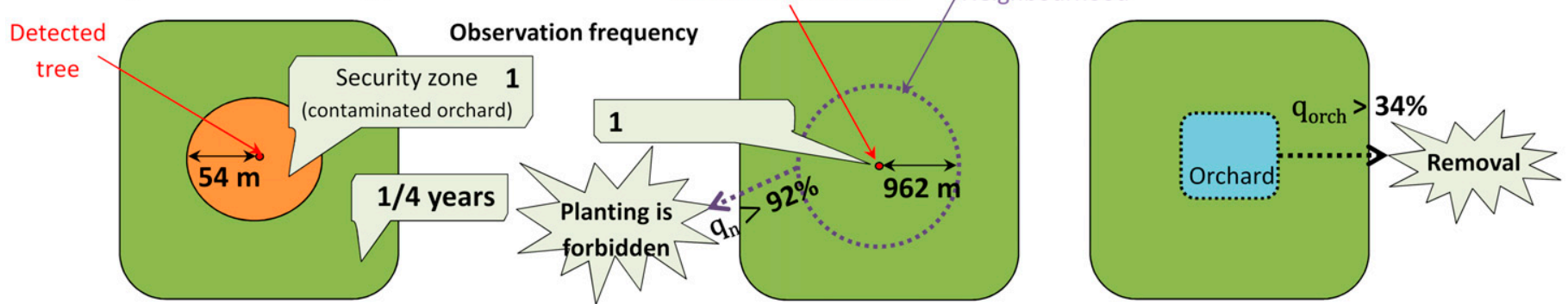

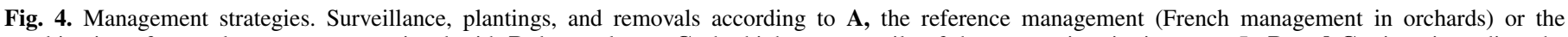

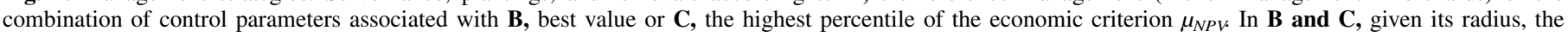

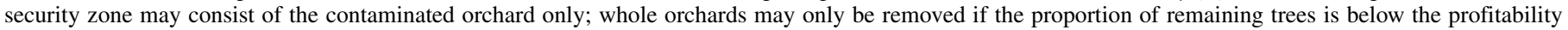
threshold $\left(\chi_{S E H D}=0.66\right)$. 
which relies on a 3-year delay before replanting, and strengthened surveillance frequencies: all orchards are surveyed every year, and those located in security zones are surveyed seven times a year (Table 2). These measures allow disease suppression despite its faster expansion. As shown with the repeated simulations in harsh epidemic contexts, these new strategies satisfy both epidemiological and economic performance criteria (Supplementary Figs. S10 and S11).

\section{DISCUSSION}

A method to improve management strategies of epidemics. In this article, we propose an innovative heuristic approach based on the sequential use of global sensitivity analysis of a simulation model to improve strategies for the management of plant disease epidemics. Although parameter ranges might have been restricted to likely values using formal (Bayesian) elicitation of expert's opinion, we chose to start from the widest meaningful ranges and narrow them down at each step of the procedure. Following the identification of the most promising control measures (step 1), the exploration of parameter space, initially large (step 2) and then, more restricted (step 3), enables us to simplify the strategy and progressively improve the control parameters. This method is based on the identification of the best strategies among a finite set of simulations. Consequently, the identified strategies are only approximately optimal, despite the wide range of explored scenarios (additional sensitivity analyses could be performed if

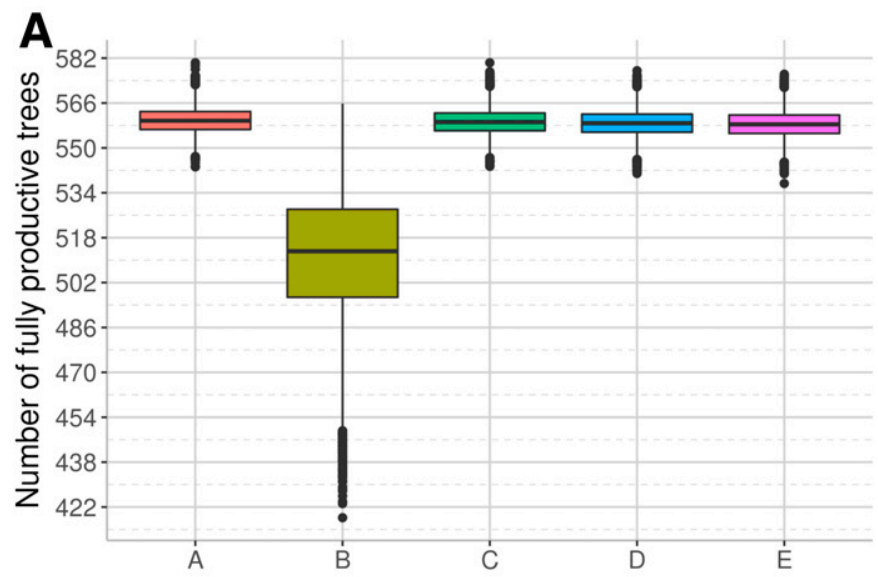

B

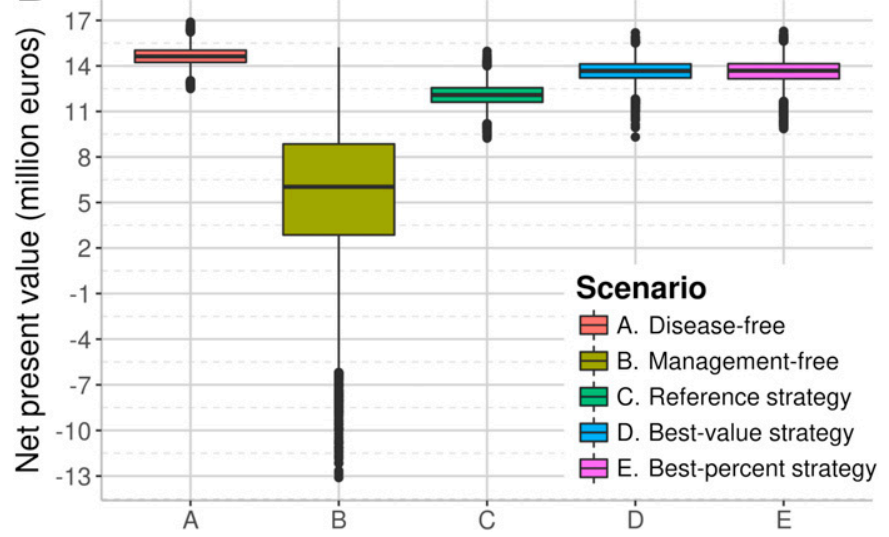

Fig. 5. Boxplots of $\mathbf{A}, Y$ (equivalent number of fully productive trees per hectare and per year) and $\mathbf{B}, N P V$ (net present value of all orchards of the landscape) after 30 years of sharka management. Different scenarios are simulated: absence of disease, absence of management, disease managed with the reference strategy (French management in orchards), or disease managed with economically improved management strategies identified through two different methods (the combination associated with the best value or the highest percentile of $\left.\mu_{N P V}\right)$. more accuracy was required for some parameters). Nevertheless, in contrast with previous studies focusing on a restricted number of control parameters (Cunniffe et al. 2015; Hyatt-Twynam et al. 2017; Parnell et al. 2010), our approach includes a wide range of management strategies and enables to jointly improve the entire set of control parameters. Point estimates of improved control parameters were identified using two different approaches (best value and best percent), resulting in two specific options to improve the reference management strategy (Fig. 4B and C). Alternatively, it could be possible to extract, from the sensitivity analyses, whole distributions of parameter values leading to the best percentile of $\mu_{N P V}$. Although this method would not account for potential interactions between parameters, it would inform on the degree of precision required on each control parameter to apply the management strategy.

Balancing costs and benefits of disease management. The selection of a relevant criterion is a crucial task in an optimization procedure. Epidemiological criteria that have been minimized for management optimization include disease incidence (Breukers et al. 2007; Holt et al. 1999; Xu and Ridout 1998), prevalence (Courcoul et al. 2011; Lurette et al. 2009), severity (Xu and Ridout 1998), propagation rate (Coutts et al. 2011; Filipe et al. 2012), basic reproduction number (Chan and Jeger 1994), proportion of infected plants at the end of the simulation (Sisterson and Stenger 2013), probability of pathogen establishment (Papaï et al. 2014), time until eradication (Barclay and Vreysen 2011; Courcoul et al. 2011; Jeger and Chan 1995; Parnell et al. 2009, 2010), or proportion/ number of removed trees required to achieve eradication (HyattTwynam et al. 2017; Parnell et al. 2009). However, to be feasible and sustainable, the choice of a management strategy must be guided by the balance between the costs induced by control actions and the economic benefits of the reduction of epidemic damage (Forster and Gilligan 2007; Fraser et al. 2004). Some studies proposed approaches to prioritize surveillance or removal options under limited resources (Cunniffe et al. 2016; Faulkner et al. 2016; Ndeffo Mbah and Gilligan 2010). Other studies proposed optimized management of different plant, animal, and human diseases accounting for the cost of management (e.g., surveillance and removal, culling, vaccination) relative to the intrinsic cost of the epidemic or the benefit of maintaining a healthy population (Cunniffe et al. 2014; Forster and Gilligan 2007; Kleczkowski et al. 2012; Thompson et al. 2018). Here, we used an economic criterion, the $N P V$, which explicitly accounts for the benefits (i.e., fruit sales) generated by the cultivation of productive hosts and the costs induced by orchard cultivation plus different control actions comprising surveillance, removal, replanting, and planting bans. By doing so, the different components of the management strategy can be optimized with explicit consideration of their cost relative to the benefit of the reduction of epidemic damage. In addition, the inclusion of a discount rate- a key element in project financial evaluation-accounts for the time value of money (i.e., the fact that the same income has less value in the future than in the present). For these reasons, the $N P V$ is a powerful criterion to identify cost-effective strategies for the management of epidemics. Although this criterion was specifically parameterized for peach orchards in this work, it could easily be used for other crops by reassessing the costs and benefits associated with their management. Finally, we also used an epidemiological criterion to assess the epidemiological efficiency of the identified improved strategies. This metric integrated the number of productive hosts across the whole production area and the whole simulation period, and it is, therefore, comparable with the "healthy area duration" used in many epidemiological models (Lo Iacono et al. 2013; Papaïx et al. 2018; Rimbaud et al. 2018b). By using this metric, we aimed to maximize the number of productive hosts rather than minimize the number of infected hosts, because the latter option does not penalize the removal of whole orchards and their replacement by young (nonproductive) trees. 
Improving sharka management. Identifying promising control measures. Based on Sobol's indices, the first sensitivity analysis highlighted the most influential control parameters on sharka epidemics in French peach orchards. These were associated with orchard removals, planting bans, and detection probability (Fig. 2). Although Sobol's method only indicates the relative influence of the parameters and does not indicate the direction of change in the output variable, it can be complemented by graphical methods or metamodels (Rimbaud et al. 2018a). Here, the smoothed curves showed the existence of an optimal detection probability and a positive correlation between the $N P V$ and the threshold values for removal and planting bans (Fig. 2, Insets). These elements highlight the importance of modeling studies designed to optimize detection efficiency (e.g., using hierarchical sampling) (Hughes et al. 1997) and removal actions (e.g., by identifying an optimal cull radius) (Cunniffe et al. 2015, 2016; Parnell et al. 2009, 2010).

Ranking model parameters by their influence on a given output variable also allows for the identification of weak contributors. Among the implemented control parameters, those associated with the modification of surveillance in response to the observed local prevalence had a negligible impact on both epidemiological and economic outcomes (Fig. 2). Therefore, in the investigated scenarios, reinforcing surveillance in highly contaminated areas may not result in improved management. Thus, the associated parameters may be discarded from the modeled management strategy without altering its efficiency. However, we assumed that each symptomatic tree had the same detection probability, regardless of its age, cultivar, and time elapsed since symptom expression. Nevertheless, field experience shows that all of these factors impact symptom expression and, consequently, visual detection. Moreover, detection events were considered independent, which enabled an excellent global detection rate after a few surveillance rounds. All of these elements could partly explain why reinforcing surveillance in highly contaminated areas had a negligible impact in our analysis but might be useful in the field.

In previous studies, the connectivity of the patch of first introduction was the most influential epidemiological parameter on sharka spread in the absence of management (Rimbaud et al. 2018a). It is still the case here in the presence of management (Fig. 2 , parameter $q_{\kappa}$ ). This result suggests that reinforced baseline surveillance of highly connected patches could be a promising control measure. This result also supports the need to match management efforts with the risk index of different patches (Barnes et al. 1999; Nelson et al. 1994; Parnell et al. 2014) or individual hosts (Hyatt-Twynam et al. 2017) and prioritize such management under limited resources (Cunniffe et al. 2016; Faulkner et al. 2016). Favoring the planting of resistant cultivars (provided that they are available) in patches with high-risk indices could also be a promising approach for disease management.

Identifying improved strategies. Our results suggest that removing whole orchards triggers higher costs than potential losses associated with maintaining undetected hosts (i.e., infectious trees in state $\mathrm{H}$ ). The identified improved strategies (targeting a costeffective management rather than eradication) are thus based on a "symptomatic host hunt" (Fig. 4B and C). However, orchard surveillance to identify these symptomatic hosts also induces high costs. Thus, in contaminated orchards, improved strategies relied on either few surveillance rounds with a good probability of detection (close to the reference value) or a greater number of surveillance rounds with a low probability of detection (one-half of the reference value, which may correspond to the surveillance of only every other row in the orchard to reduce the cost of a surveillance round). Overall, although surveying an orchard more than once a year multiplies the costs, it favors the detection of infected trees that may remain undetected after the first round of surveillance. It might be interesting to investigate the potential of alternative detection protocols, like serological or molecular methods, which are used for the management of several perennial plant epidemics (including sharka in the United States) (Gougherty et al. 2015). Such investigation may be performed with our model by changing the relationship between the probability of detection and the cost of surveillance.

Our results indicate that the current French management of sharka should already be very efficient in controlling the disease (Fig. 5A); consequently, no major improvement should be expected with respect to the epidemiological criterion. In contrast, the economic criterion shows that the French strategy is associated with substantial costs (Fig. 5B). We identified improved strategies, which should be epidemiologically as efficient as the current French strategy but less expensive; also, they are simpler and hence, easier to implement in the field. These strategies are based on simplified surveillance procedures and the absence of removal zones (Fig. 4). Nevertheless, the default surveillance frequency (for orchards located outside of focal and security zones) is increased to once every 4 (instead of 6) years. This change enables the removal of newly introduced infectious trees more promptly after the end of the latent period, which was shown to decrease the overall management costs (Cunniffe et al. 2016).

Several assumptions may influence the improved strategies identified here. In particular, the ability to detect symptomatic hosts may have been overestimated as explained above, which should result in practice in a slight undercontrol. Consequently, in the field and under certain conditions, it might still be interesting to rogue whole orchards to remove hard to detect diseased trees. Furthermore, we assumed that all orchards had the same susceptibility to Plum pox virus. However, young plants may be more susceptible than older ones (Astier et al. 2007). Thus, our results may underestimate the importance of surveying young orchards.

Despite these considerations, the best-value and best-percent strategies deserve to be considered to improve the cost-efficiency of sharka management. The common feature of these options is a simplification of surveillance and removal measures that reduces management costs while maintaining good epidemiological performance. However, our results show that these strategies may fail to control disease in harsh epidemic contexts. For these situations, the flexibility of our approach allowed us to identify new strategies, illustrating its general ability to find improved combinations of control parameters in a given epidemic context. Furthermore, such strategies are relevant to the other (perennial) plant diseases that are managed through surveillance, removals, and planting restrictions. We note, however, that some control actions (for which we had no cost or benefit values) were not investigated in this work, like nursery protection measures, planting at different densities, or the use of resistant prunus trees. In addition, vector control by insecticides was not studied here, because insecticides generally fail to control the spread of nonpersistent viruses, such as Plum pox virus (Perring et al. 1999; Rimbaud et al. 2015).

\section{ACKNOWLEDGMENTS}

We thank G. Labonne and S. Grizard for constructing the surveillance database; SRAL RA, FREDON 30, and especially, J. Aymard for expertise in prunus cultivation; D. R. J. Pleydell for programming the first version of the model; P. H. Thrall for reviewing a previous version of this manuscript; the reviewers and editor for their valuable comments; the INRA BioSP and the CIRAD SouthGreen bioinformatics platforms; and L. Houde and S. Ravel for providing support.

\section{LITERATURE CITED}

Agreste. 2013. Infos rapides-Fruits-Pêches. Report no. 5. http://www. agreste.agriculture.gouv.fr/IMG/pdf/conjinfofru201309pech.pdf

Agreste. 2014. Infos rapides-Fruits-Pêches. Report no. 5. http://www. agreste.agriculture.gouv.fr/IMG/pdf/conjinfofru201409pech.pdf

Agreste. 2015. Infos rapides-Fruits-Pêches. Report no. 2. http://www. agreste.agriculture.gouv.fr/IMG/pdf/conjinfofru201506pech.pdf 
Astier, S., Albouy, J., Maury, Y., Robaglia, C., and Lecoq, H. 2007. Principles of Plant Virology. Science Publishers, Enfield, NH.

Barclay, H. J., and Vreysen, M. J. B. 2011. A dynamic population model for tsetse (Diptera: Glossinidae) area-wide integrated pest management. Popul. Ecol. 53:89-110.

Barnes, J. M., Trinidad-Correa, R., Orum, T. V., Felix-Gastelum, R., and Nelson, M. R. 1999. Landscape ecology as a new infrastructure for improved management of plant viruses and their insect vectors in agroecosystems. Ecosyst. Health 5:26-35.

Breukers, A., van der Werf, W., Kleijnen, J. P. C., Mourits, M., and Lansink, A. O. 2007. Cost-effective control of a quarantine disease: A quantitative exploration using "design of experiments" methodology and bio-economic modeling. Phytopathology 97:945-957.

Cambra, M., Capote, N., Myrta, A., and Llácer, G. 2006. Plum pox virus and the estimated costs associated with sharka disease. EPPO Bull. 36:202-204.

Chan, M. S., and Jeger, M. J. 1994. An analytical model of plant virus disease dynamics with roguing and replanting. J. Appl. Ecol. 31:413-427.

Courcoul, A., Monod, H., Nielen, M., Klinkenberg, D., Hogerwerf, L., Beaudeau, F., and Vergu, E. 2011. Modelling the effect of heterogeneity of shedding on the within herd Coxiella burnetii spread and identification of key parameters by sensitivity analysis. J. Theor. Biol. 284:130-141.

Coutts, S. R., van Klinken, R. D., Yokomizo, H., and Buckley, Y. M. 2011. What are the key drivers of spread in invasive plants: Dispersal, demography or landscape and how can we use this knowledge to aid management? Biol. Invasions 13:1649-1661.

Cunniffe, N. J., Cobb, R. C., Meentemeyer, R. K., Rizzo, D. M., and Gilligan, C. A. 2016. Modeling when, where, and how to manage a forest epidemic, motivated by sudden oak death in California. Proc. Natl. Acad. Sci. USA 113:5640-5645.

Cunniffe, N. J., Laranjeira, F. F., Neri, F. M., DeSimone, R. E., and Gilligan, C. A. 2014. Cost-effective control of plant disease when epidemiological knowledge is incomplete: Modelling bahia bark scaling of citrus. PLOS Comput. Biol. 10:e1003753.

Cunniffe, N. J., Stutt, R. O. J. H., DeSimone, R. E., Gottwald, T. R., and Gilligan, C. A. 2015. Optimising and communicating options for the control of invasive plant disease when there is epidemiological uncertainty. PLOS Comput. Biol. 11:e1004211.

Dallot, S., Gottwald, T., Labonne, G., and Quiot, J.-B. 2003. Spatial pattern analysis of sharka disease (Plum pox virus strain $\mathrm{M}$ ) in peach orchards of southern France. Phytopathology 93:1543-1552.

Faulkner, K. T., Robertson, M. P., Rouget, M., and Wilson, J. R. U. 2016. Border control for stowaway alien species should be prioritised based on variations in establishment debt. J. Environ. Manage. 180:301-309.

Filipe, J. A. N., Cobb, R. C., Meentemeyer, R. K., Lee, C. A., Valachovic, Y. S., Cook, A. R., Rizzo, D. M., and Gilligan, C. A. 2012. Landscape epidemiology and control of pathogens with cryptic and long-distance dispersal: Sudden oak death in northern Californian forests. PLOS Comput. Biol. 8:e1002328.

Forster, G. A., and Gilligan, C. A. 2007. Optimizing the control of disease infestations at the landscape scale. Proc. Natl. Acad. Sci. USA 104:4984-4989.

FranceAgriMer. 2015. Observatoire de la formation des prix et des marges des produits alimentaires-Prix à l'expédition et au détail en GMS de la pêche et de la nectarine. https://observatoire-prixmarges.franceagrimer.fr/resultats/ Pages $/$ ResultatsFilieres.aspx ?idfiliere $=4 \&$ sousmenuid=83\& type=Tableau

Fraser, C., Riley, S., Anderson, R. M., and Ferguson, N. M. 2004. Factors that make an infectious disease outbreak controllable. Proc. Natl. Acad. Sci. USA 101:6146-6151.

Gottwald, T. R., Wierenga, E., Luo, W. Q., and Parnell, S. 2013. Epidemiology of plum pox 'D' strain in Canada and the USA. Can. J. Plant Pathol. 35:442-457.

Gougherty, A. V., Pazdernik, K. T., Kaiser, M. S., and Nutter, F. W. 2015. Evaluation of sampling and testing efficiencies of Plum pox virus eradication programs in Pennsylvania and Ontario. Plant Dis. 99:1247-1253.

Holt, J., Colvin, J., and Muniyappa, V. 1999. Identifying control strategies for tomato leaf curl virus disease using an epidemiological model. J. Appl. Ecol. 36:625-633.

Hughes, G., McRoberts, N., Madden, L. V., and Gottwald, T. R. 1997. Relationships between disease incidence at two levels in a spatial hierarchy. Phytopathology 87:542-550.

Hyatt-Twynam, S. R., Parnell, S., Stutt, R. O. J. H., Gottwald, T. R., Gilligan, C. A., and Cunniffe, N. J. 2017. Risk-based management of invading plant disease. New Phytol. 214:1317-1329.

INSEE. 2015. Indice des prix à la consommation-Secteurs conjoncturels (mensuel, ensemble des ménages, métropole + DOM, base 1998)Ensemble hors tabac. https://www.insee.fr/fr/bases-de-donnees/bsweb/serie.asp?idbank $=000641194$

Jeger, M. J., and Chan, M. S. 1995. Theoretical aspects of epidemics: Uses of analytical models to make strategic management decisions. Can. J. Plant Pathol. 17:109-114.
Jeger, M. J., Madden, L. V., and van den Bosch, F. 2018. Plant virus epidemiology: Applications and prospects for mathematical modeling and analysis to improve understanding and disease control. Plant Dis. 102: 837-854.

JORF. 2011. Arrêté du 17 mars 2011 relatif à la lutte contre le Pum Pox Virus, agent causal de la maladie de la Sharka, sur les végétaux sensibles du genre Prunus. JORF n0067 du 20 mars 2011, NOR: AGRG1105295A. https:// www.legifrance.gouv.fr/affichTexte.do?cidTexte=JORFTEXT000023728913\& dateTexte $=\&$ categorieLien $=$ id

Kleczkowski, A., Oleś, K., Gudowska-Nowak, E., and Gilligan, C. A. 2012. Searching for the most cost-effective strategy for controlling epidemics spreading on regular and small-world networks. J. R. Soc. Interface 9: 158-169.

Labonne, G., Yvon, M., Quiot, J.-B., Avinent, L., and Llácer, G. 1995. Aphids as potential vectors of Plum pox virus: Comparison of methods of testing and epidemiological consequences. Acta Hortic. 386:207-218.

Lo Iacono, G., van den Bosch, F., and Gilligan, C. A. 2013. Durable resistance to crop pathogens: An epidemiological framework to predict risk under uncertainty. PLOS Comput. Biol. 9:e1002870.

Lurette, A., Touzeau, S., Lamboni, M., and Monod, H. 2009. Sensitivity analysis to identify key parameters influencing Salmonella infection dynamics in a pig batch. J. Theor. Biol. 258:43-52.

Ndeffo Mbah, M. L., and Gilligan, C. A. 2010. Optimization of control strategies for epidemics in heterogeneous populations with symmetric and asymmetric transmission. J. Theor. Biol. 262:757-763.

Nelson, M. R., Felix-Gastelum, R., Orum, T. V., Stowell, L. J., and Myers, D. E. 1994. Geographic information systems and geostatistics in the design and validation of regional plant virus management programs. Phytopathology 84:898-905.

Papaix, J., Adamczyk-Chauvat, K., Bouvier, A., Kiêu, K. S. T., Lannou, C., and Monod, H. 2014. Pathogen population dynamics in agricultural landscapes: The Ddal modelling framework. Infect. Genet. Evol. 27:509-520.

Papaï, J., Rimbaud, L., Burdon, J. J., Zhan, J., and Thrall, P. H. 2018. Differential impact of landscape-scale strategies for crop cultivar deployment on disease dynamics, resistance durability and long-term evolutionary control. Evol. Appl. 11:705-717.

Parnell, S., Gottwald, T. R., Gilligan, C. A., Cunniffe, N. J., and van den Bosch, F. 2010. The effect of landscape pattern on the optimal eradication zone of an invading epidemic. Phytopathology 100:638-644.

Parnell, S., Gottwald, T. R., Riley, T., and van den Bosch, F. 2014. A generic risk-based surveying method for invading plant pathogens. Ecol. Appl. 24: 779-790.

Parnell, S., Gottwald, T. R., van den Bosch, F., and Gilligan, C. A. 2009. Optimal strategies for the eradication of asiatic citrus canker in heterogeneous host landscapes. Phytopathology 99:1370-1376.

Parnell, S., van den Bosch, F., Gottwald, T., and Gilligan, C. A. 2017. Surveillance to inform control of emerging plant diseases: An epidemiological perspective. Annu. Rev. Phytopathol. 55:591-610.

Perring, T. M., Gruenhagen, N. M., and Farrar, C. A. 1999. Management of plant viral diseases through chemical control of insect vectors. Annu. Rev. Entomol. 44:457-481.

Pleydell, D. R. J., Soubeyrand, S., Dallot, S., Labonne, G., Chadœuf, J., Jacquot, E., and Thébaud, G. 2018. Estimation of the dispersal distances of an aphidborne virus in a patchy landscape. PLOS Comput. Biol. 14:e1006085.

Pujol, G., Iooss, B., and Janon, A. 2017. Sensitivity: Global Sensitivity Analysis of Model Outputs. R Package Version 1.11.0. https://cran.r-project. org/web/packages/sensitivity/index.html

Quinet, E. 2013. L'évaluation socioéconomique des investissements publics. Report No. 1. https://www.strategie.gouv.fr/sites/strategie.gouv.fr/files/archives/ CGSP_Evaluation_socioeconomique_17092013.pdf

Quiot, J.-B., Labonne, G., Boeglin, M., Adamolle, C., Renaud, L. Y., and Candresse, T. 1995. Behaviour of two isolates of Plum pox virus inoculated on peach and apricot trees: First results. Acta Hortic. 386:290-298.

R Core Team. 2012. R: A Language and Environment for Statistical Computing. R Foundation for Statistical Computing, Vienna, Austria.

Rimbaud, L., Bruchou, C., Dallot, S., Pleydell, D. R. J., Jacquot, E., Soubeyrand, S., and Thébaud, G. 2018a. Using sensitivity analysis to identify key factors for the propagation of a plant epidemic. R. Soc. Open Sci. 5:171435.

Rimbaud, L., Dallot, S., Gottwald, T., Decroocq, V., Jacquot, E., Soubeyrand, S., and Thébaud, G. 2015. Sharka epidemiology and worldwide management strategies: Learning lessons to optimize disease control in perennial plants. Annu. Rev. Phytopathol. 53:357-378.

Rimbaud, L., Papaïx, J., Rey, J.-F., Barrett, L. G., and Thrall, P. H. 2018 b. Assessing the durability and efficiency of landscape-based strategies to deploy plant resistance to pathogens. PLOS Comput. Biol. 14:e1006067.

Saltelli, A., Ratto, M., Andres, T., Campolongo, F., Cariboni, J., Gatelli, D., Saisana, M., and Tarantola, S. 2008. Global Sensitivity Analysis, The Primer. Wiley, Chichester, UK. 
Sisterson, M. S., and Stenger, D. C. 2013. Roguing with replacement in perennial crops: Conditions for successful disease management. Phytopathology 103:117-128.

Sobol, I. M. 1976. Uniformly distributed sequences with an additional uniform property. USSR Comput. Math. Math. Phys. 16:236-242.

Sobol, I. M. 1993. Sensitivity analysis for non-linear mathematical models. Math. Modell. Comput. Exp. 1:407-414.

Sutic, D. 1971. Etat des recherches sur le virus de la sharka. Ann. Phytopathol. 161-170.
Thompson, R. N., Gilligan, C. A., and Cunniffe, N. J. 2018. Control fast or control smart: When should invading pathogens be controlled? PLOS Comput. Biol. 14:e1006014.

Wuertz, D., Setz, T., and Chalabi, Y. 2017. fOptions: Rmetrics-Pricing and Evaluating Basic Options. R Package Version 3010.83. https://cran.r-project. org/web/packages/fOptions/index.html

Xu, X. M., and Ridout, M. S. 1998. Effects of initial epidemic conditions, sporulation rate, and spore dispersal gradient on the spatio-temporal dynamics of plant disease epidemics. Phytopathology 88:1000-1012. 